\title{
The double effect of walnut septum extract (Juglans regia L.) counteracts A172 glioblastoma cell survival and bacterial growth
}

\author{
CARLO GENOVESE ${ }^{1,2^{*}}$, MARIA TERESA CAMBRIA ${ }^{3 *}$, FLORIANA D'ANGELI $^{3}$, \\ ALESSANDRO PAOLO ADDAMO $^{1}$, GIUSEPPE ANTONIO MALFA ${ }^{4}$, LAURA SIRACUSA ${ }^{5}$, \\ LUANA PULVIRENTI ${ }^{5}$, CARMELINA DANIELA ANFUSO ${ }^{3}$, GABRIELLA LUPO $^{3}$ and MARIO SALMERI ${ }^{1}$ \\ ${ }^{1}$ Department of Biomedical and Biotechnological Sciences, Microbiology Section, University of Catania; ${ }^{2}$ Nacture S.r.l., \\ Spin-off University of Catania; ${ }^{3}$ Department of Biomedical and Biotechnological Sciences, Biochemistry Section, \\ University of Catania, I-95123; ${ }^{4}$ Department of Drug Science, Biochemistry Section, University of \\ Catania, I-95125 Catania; ${ }^{5}$ Istituto di Chimica Biomolecolare del CNR, I-95126 Catania, Italy
}

Received April 28, 2020; Accepted June 25, 2020

DOI: $10.3892 / \mathrm{ijo} .2020 .5130$

\begin{abstract}
Walnut (Juglans regia L.) is considered to be a 'superfood' for its multiple protective actions on human health. Walnut extracts have proven antitumor activity in different cancer cell lines. However, the efficacy of septum extract against glioblastoma has still not been investigated. Glioblastoma is the most difficult type of brain cancer to treat. The standard therapy, based on temozolomide, causes several side effects, including neutropenia and lymphocytopenia, which often favor the onset of opportunistic infections. In the present study, the chemical profile of the Sicilian walnut septum ethanolic extract was analyzed using high-performance liquid chromatography (HPLC)-diode array detection and HPLC-electrospray ionization tandem mass spectrometry. The potential cytostatic activity of the extract against the human A172 glioblastoma cell line was investigated and the results showed that the extract could decrease cancer cell proliferation and migration. Using cytofluorimetric analyses and caspase-3 assays, the pro-apoptotic action of walnut extract was demonstrated. Furthermore, the evaluation of the antibacterial activity highlighted the efficacy of the extract in reducing Gram-positive and Gram-negative bacterial growth, most of which were resistant to the antibiotic, ciprofloxacin. Finally, Prediction of Activity Spectra for Substances analysis showed the predicted antitumor and antibacterial activity of HPLC detected compounds. The
\end{abstract}

Correspondence to: Gabriella Lupo and Carmelina Daniela Anfuso, Department of Biomedical and Biotechnological Sciences, Biochemistry Section, University of Catania, 97 Via Santa Sofia, I-95123 Catania, Italy

E-mail: gabriella.lupo@unict.it

E-mail: daniela.anfuso@unict.it

*Contributed equally

Key words: glioblastoma, minimal inhibitory concentration, gram-positive and gram-negative bacterial strains, walnuts septum, Juglans regia $L$., cancer cell proliferation and migration, apoptosis promising results could provide novel perspective in the field of chemotherapeutic co-adjuvants.

\section{Introduction}

Plant extracts are becoming increasingly important, as a prominent source of active compounds, which are able to interfere with biological activities in eukaryotic and prokaryotic cells (1). In traditional medicine, the crude extracts of different parts of plants were formerly used, as a folk remedy for a large variety of pathologies, which is due to the biological proprieties of the molecules present in the extracts (2).

Juglans regia L.(J.regia), the common walnut, belongs to the Juglandaceae family and is rich, in all parts, in various chemical products, with antimicrobial, anti-biofilm, anti-inflammatory and anti-oxidant activities $(3,4)$. Accordingly, the fresh green fruit, the peel, the skin, the leaves, the bark and the root have been widely used in food, cosmetic and pharmaceutical industries (5). The brown and thin leathery covering of the kernel contains a high concentration of phenolic compounds and protects the kernel from microbial attack (6). The antimicrobial activity of walnut tree branches and walnut pellicle extract has been shown (4,7). Furthermore, the anticancer activity of phenolic compounds and, in particular, the anti-proliferative effect of J. regia extracts on human breast and oral cancer cell lines has been demonstrated $(8,9)$. However, despite the proven antitumor effects on different cancer cell lines, the efficacy of walnut extract on glioblastoma cells is still currently unknown.

Brain cancers are a heterogeneous group of tumors deriving from neoplastic transformation of brain cells (primary tumor) or from the invasion of cancer cells originating from another part of the body (secondary tumor). Data regarding the incidence rates of primary tumors of the central nervous system are not encouraging. Specifically, glioblastoma, the most aggressive form of astrocytoma, accounts for $50 \%$ of all gliomas and in 2018, it was responsible for $2.5 \%$ cancer-associated death, worldwide (10-13). Using molecular and histological techniques, it is possible to recognize different hallmarks of malignancy, such as intense proliferation, cell heterogeneity, genomic point aberrations, high vascularization and invasion $(14,15)$. 
The development of innovative treatments and novel therapeutic strategies are areas of active research, aimed at improving the quality of life and life expectancy of patients with cancer (16-20). However, despite the enormous progress in this field, even with the introduction of immunotherapy (21), brain tumors are still associated with high mortality rates (22). The standard therapy for glioblastoma requires three different steps: surgical resection, external beam radiation therapy and chemotherapy (23).

It is worth noting that one of the complications of antitumor therapy is infectious diseases, due to immunosuppression in patients with cancer. In this regard, it has been reported that concomitant radio- and chemotherapy treatment causes neutropenia and lymphocytopenia, thus promoting opportunistic infection by Pneumocystis carinii pneumonia in patients with grade III anaplastic astrocytoma and grade IV glioblastoma multiforme (24). Therefore, the emergence of opportunistic infections in patients with cancer depends on the cytotoxic effects of chemotherapeutic agents, that prevent the active reproduction of proliferating cells, including cells in the immune system. This leads to a reduction in the host defense system (25).

Several studies have demonstrated the beneficial effects of walnut consumption for the brain. In particular, in both animal and human studies it was demonstrated that a walnut diet reduces the brain-accumulation of damaged proteins and reduces brain inflammation associated with aging (26-28). A previous study has highlighted the strong antioxidant effects of walnut septum extracts (29), suggesting a possible role of such extracts in the maintenance of brain homeostasis $(30,31)$. Therefore, these studies have demonstrated that walnut consumption or walnut extracts are protective for brain aging (32), paving the way for further studies investigating brain tumors.

Thus, the aim of the present study was to investigate the effect of the walnut septum extract against one of the most aggressive brain tumors. Using high-performance liquid chromatography-diode array detection (HPLC/DAD) and HPLC-electrospray ionization tandem mass spectrometry (HPLC/ESI-MS) analysis, the phytochemical composition of Sicilian walnut fruit septum ethanolic extract was obtained. The potential cytostatic and cytotoxic properties of the extract against human glioblastoma cell line and the antibacterial activity against different Gram-positive and Gram-negative bacterial strains were also investigated. Using the Prediction of Activity Spectra for Substances (PASS) analysis, the possible bioactive compounds responsible for the biological effect of walnut septum extract was also investigated.

\section{Materials and methods}

Chemicals. Unless otherwise stated, all reagents and solvents were of analytical grade and used without further purification. Pure reference standards: gallic acid, vanillic acid, ellagic acid, p-coumaric acid and quercetin 3-O-glucoside were purchased from Sigma Aldrich (Merck KGaA), while flavan-3-ols catechin, epigallocatechin and epigallocatechingallate were obtained from Extrasynthese. HPLC grade water, acetonitrile and methanol were purchased from VWR International, LLC (Avantor).
Plant material and preparation of the extract. Walnuts were collected in Trecastagni (Catania, Italy). The specimen was authenticated by the Botanist Prof. Salvatore Ragusa, Department of Health Sciences, University of Catanzaro, (Catania, Italy). A voucher specimen of walnut was deposited in the herbarium of the same Department. The preparation of walnuts septum extract was conducted as previously described by Acquaviva et al (4). Briefly, $10 \mathrm{~g}$ of dried J. regia septum were ground using a pestle and mortar. Ethanolic extract was obtained by maceration of $10 \mathrm{~g}$ pulverized walnut septum in $50 \mathrm{ml} \mathrm{96 \%} \mathrm{ethanol} \mathrm{(Merck} \mathrm{KGaA)} \mathrm{for} 48 \mathrm{~h}$, under constant shaking at room temperature. The extraction process was repeated four times. The four aliquots were combined together $(200 \mathrm{ml})$, filtered and evaporated to a dry product, under reduced pressure with a rotatory evaporator (Stuart RE300; Thermo Fisher Scientific, Inc.). The weight of the dried extract was $0.55 \mathrm{~g}$ and it was stored at $4^{\circ} \mathrm{C}$ in an airtight glass vial until further use. The extract obtained was then solubilized in $96 \%$ ethanol and used for the experiments.

HPLC/DAD and HPLC/ESI-MS analyses. Chromatographic analyses were performed using an Ultimate3000 UHPLC focused instrument equipped with a binary high-pressure pump, a Photodiode Array detector, a Thermostatted Column Compartment and an Automated Sample Injector (Thermo Fisher Scientific, Inc.). The collected data was processed using a Chromeleon Chromatography Information Management System v6.80(ThermoFisher Scientific,Inc.). Chromatographic runs were performed using a reverse-phase column (Gemini $\mathrm{C} 18 ; 250 \times 4.6 \mathrm{~mm} ; 5 \mu \mathrm{m}$ particle size) equipped with a guard column (Gemini C18 4 x $3.0 \mathrm{~mm} ; 5 \mu \mathrm{m}$ particle size) (both from Phenomenex, Inc.). Walnut fruit septum polyphenols were eluted using a gradient of B $(2.5 \%$ formic acid in acetonitrile) in A (2.5\% formic acid in water): 0 min: $5 \% \mathrm{~B} ; 10 \mathrm{~min}$ : $15 \%$ B; 30 min: $25 \%$ B; 35 min: $30 \%$ B; 50 min: $90 \%$ B; $57 \mathrm{~min}$ then held for a further $7 \mathrm{~min}, 100 \% \mathrm{~B}$. The solvent flow rate was $1 \mathrm{~mL} / \mathrm{min}$, the temperature was maintained at $25^{\circ} \mathrm{C}$ and the injector volume selected was $10 \mu \mathrm{l}$. Quantification was performed at $280 \mathrm{~nm}$ for organic acids (protocatechuic and vanillic acid) using vanillic acid as the reference (R2, 0.9999), while gallic acid and its derivatives [including hexahydroxydiphenol (HHDP) derivatives] were quantified at the same wavelength using gallic acid (R2, 0.9998) as an external standard. Similarly, quantification of flavan-3-ols was performed at $280 \mathrm{~nm}$ using catechin (R2, 0.9999), epigallocatechin (R2, 0,9999) and epigallocatechin gallate (R2, 0.9998) as references, whilst p-coumaric acid was quantified at $330 \mathrm{~nm}$ using the corresponding commercially available material (R2, 0.9999). Quercetin 3-O-glucoside (R2, 0.9998) was used to quantify all flavonols present in the extract; ellagic acid (R2, 0.9997) was used as the reference for the quantification of its own derivatives and valoneic acid dilactone. Flavonols, ellagic acids and valoneic acid derivatives were all quantified at $350 \mathrm{~nm}$. To unambiguously identify the chromatographic signals and to confirm peak assignments, HPLC/ESI-MS analyses were also performed. The HPLC apparatus used was the same as aforementioned, whilst ESI MS spectra were acquired using a Thermo Scientific Exactive Plu Orbitra MS (Thermo Fisher Scientific, Inc.), using a heated electrospray ionization (HESI II) interface. MS spectra were recorded 
operating in negative ion mode, in the $\mathrm{m} / \mathrm{z}$ range $120-1,500$, at a resolving power of 25,000 (full-width-at-half-maximum, at $\mathrm{m} / \mathrm{z}$ 200, full-width-at-half-maximum, resulting in a scan rate of $>1.5$ scans/sec when using automatic gain control target of $1.0 \times 10^{6}$ and a C-trap inject time of $250 \mathrm{~ms}$, under the following conditions: Capillary temperature, $300^{\circ} \mathrm{C}$; nebulizer gas (nitrogen) with a flow rate 60 arbitrary units; auxiliary gas flow rate 10 arbitrary units; source voltage $3 \mathrm{kV}$; capillary voltage $82.5 \mathrm{~V}$; tube lens voltage $85 \mathrm{~V}$. The Orbitrap MS system was tuned and calibrated in positive modes, by infusion of solutions of a standard mixture of SDS (Mr 265.17 Da), sodium taurocholate ( $\mathrm{Mr} 514.42 \mathrm{Da})$ and Ultramark ( $\mathrm{Mr}$ $1621 \mathrm{Da}$ ). Data acquisition and analyses were performed using the Excalibur software v4.3 (Thermo Fisher Scientific, Inc.). Analyses were all performed in triplicate.

Cell culture and treatment. Human glioblastoma cells (A172), were purchased from American Type Culture Collection (ATCC) and maintained in Dulbecco's modified Eagle's medium(DMEM; ATCC $^{\circledR} 30-2002^{\mathrm{TM}}$; ATTC) containing $4 \mathrm{mM}$ L-glutamine, $4,500 \mathrm{mg} / \mathrm{l}$ glucose, $1 \mathrm{mM}$ sodium pyruvate and $1,500 \mathrm{mg} / \mathrm{l}$ sodium bicarbonate, supplemented with $10 \%$ heat-inactivated fetal bovine serum (FBS; Sigma-Aldrich; Merck KGaA) and $1 \%$ penicillin/streptomycin, at $37^{\circ} \mathrm{C}$ in a humidified incubator with $5 \% \mathrm{CO}_{2}$. Human foreskin fibroblasts (HFF-1) were also from ATCC and were used as a normal control, as previously described (33). Cells were cultured in DMEM (ATCC ${ }^{\circledR}$ 30-2002 $2^{\text {rs }}$; ATCC) supplemented with $15 \%$ heat-inactivated FBS (Sigma-Aldrich; Merck KGaA) and $1 \%$ penicillin/streptomycin, at $37^{\circ} \mathrm{C}$ in a humidified incubator with $5 \% \mathrm{CO}_{2}$. Cells were passaged once a week following trypsinization and replaced with new medium twice weekly.

The A172 and HFF-1 cell lines were cultured in presence or absence (control) of increasing concentrations of walnut septum extract, ranging from 8.75 to $140 \mu \mathrm{g} / \mathrm{ml}$, for 24 and $48 \mathrm{~h}$. All the treatments were performed using culture medium containing 1\% FBS (starvation conditions) to minimize cell proliferation, induced by the medium (34). The final ethanol concentration (used for extract solubilization) in the culture medium was $0.05 \%$. This low concentration excludes any possible effect of the vehicle (ethanol) on treated cells (35).

MTT assay. To verify the ability of the natural extract to affect A172 and HFF-1 cell viability, the MTT assay was used (Thermo Fisher Scientific, Inc.). Cell lines were seeded in 96-well plates, at a density of $1.5 \times 10^{4}$ per well and incubated overnight at $37^{\circ} \mathrm{C}$ prior to experimentation. Following which, cells were treated with scalar concentrations of walnut septum extract $(8.75,17.5,35,70,140 \mu \mathrm{g} / \mathrm{ml})$ for 24 and $48 \mathrm{~h}$ then, $10 \mu \mathrm{l}$ MTT reagent $(5 \mathrm{mg} / \mathrm{ml})$ was added to each well and the cells were incubated for $3 \mathrm{~h}$ at $37^{\circ} \mathrm{C}$. The formazan crystals were solubilized with $100 \mu \mathrm{l}$ DMSO and plates were shaken for $10 \mathrm{~min}$. The absorbance was measured at $570 \mathrm{~nm}$ using a plate reader (Synergy 2-BioTek; Agilent Technologies, Inc.).

Cell proliferation. Proliferation of the human glioblastoma cell line was determined using crystal violet (Merck KGaA) staining assay. Briefly, A172 cells were cultured in 96-well plates, at a density of $1.5 \times 10^{4}$ per well and incubated for $18 \mathrm{~h}$ at $37^{\circ} \mathrm{C}$ to enable adhesion of cells to the wells. Subsequently, cells were treated with $70 \mu \mathrm{g} / \mathrm{ml}$ walnut septum extract for $24 \mathrm{~h}$ and $48 \mathrm{~h}$. At the appropriate time point, the medium was removed, and the cells were washed twice with PBS. After washing, control and treated cells were observed using a phase contrast optical microscope and images were obtained using an inverted Leica DM IRB microscope equipped with a CCD camera (Leica Microsystems, Inc.). Subsequently, $100 \mu 1$ $0.5 \%$ crystal violet staining solution was added to each well and then the cells were incubated for $10 \mathrm{~min}$ at room temperature. Following three washes with PBS, the plate was air-dried, without the lid for $2 \mathrm{~h}$ at room temperature. After the addition of $200 \mu 10.1 \%$ SDS solution, the plates were shaken for $10 \mathrm{~min}$ and read at $570 \mathrm{~nm}$ using a plate reader (Synergy 2-BioTek; Agilent Technologies, Inc.).

Cell migration. The migration ability of the A172 cell line was measured using a standard wound-healing assay, performed as previously described (14). Migration was captured using an inverted Leica DM IRB microscope equipped with a CCD camera (Leica Microsystems, Inc.). The ability of the A172 cells migrate into the wound was evaluated by determining the percentage of growth area into the wound compared with the initial starting point at time $0(\mathrm{t} 0)$. According to Ammann et al (36), to calculate the percentage of growth, the areas were measured by tracing the boundary of growth with the ImageJ software (ImageJ bundled with 64-bit Java v1.8.0_112; National Institutes of Health). Time 0 represents the time after which the wound was created for all conditions: control (cells grown with $1 \%$ FBS for 24 and $48 \mathrm{~h}$ ) and treated cells (cells grown with $1 \%$ FBS and $70 \mu \mathrm{g} / \mathrm{ml}$ walnut septum extract for 24 and $48 \mathrm{~h}$ ). The percentage migration was determined using the following calculation: Percentage migration $=$ $\left[\left(\mathrm{A}_{\text {initial }}-\mathrm{A}_{\text {migration }}\right) / \mathrm{A}_{\text {initial }} \times 100\right.$, where $\mathrm{A}_{\text {initial }}$ was the initial wound area and $\mathrm{A}_{\text {migration }}$ was the wound area following cell migration.

Caspase-3 colorimetric protease assay. Caspase-3 activity was analyzed using A172 cell lysates with a colorimetric protease assay (Thermo Fisher Scientific, Inc.) as previously described (37). The absorbance was read using a microplate reader (Synergy 2-BioTek; Agilent Technologies, Inc.) at $400 \mathrm{~nm}$.

Flow cytometery analysis. The A172 cell line was seeded in 6 -well plates, at a density of $3 \times 10^{4}$ cells. Following treatment with $70 \mu \mathrm{g} / \mathrm{ml}$ walnut septum extract for 24 and $48 \mathrm{~h}$, cells were collected and washed with PBS, then subsequently stained with Annexin V-FITC/propidium iodide (PI), in Annexin-V binding buffer (Sigma-Aldrich; Merck KGaA) for $10 \mathrm{~min}$ at $20^{\circ} \mathrm{C}$ (protected from light), according to the manufacturer's instructions. Samples were analyzed immediately using an Amnis ${ }^{\circledR}$ FlowSight ${ }^{\circledR}$ flow cytometer (Luminex Corporation). A $488 \mathrm{~nm}$ laser was used for excitation. Bright field (430-480 nm), Annexin V-FITC (505-560 nm) and PI (595-642 nm) analysis was focused on at least 5,000 cell events per sample. INSPIRE ${ }^{\circledR}$ software (vMark II) was used to setup, calibrate and obtain spectral compensation, while IDEAS ${ }^{\circledR}$ software (v6.0) (both EMD Millipore; Merck KGaA) was used to quantify the number of cell subpopulations (healthy, apoptotic and necrotic cells). 


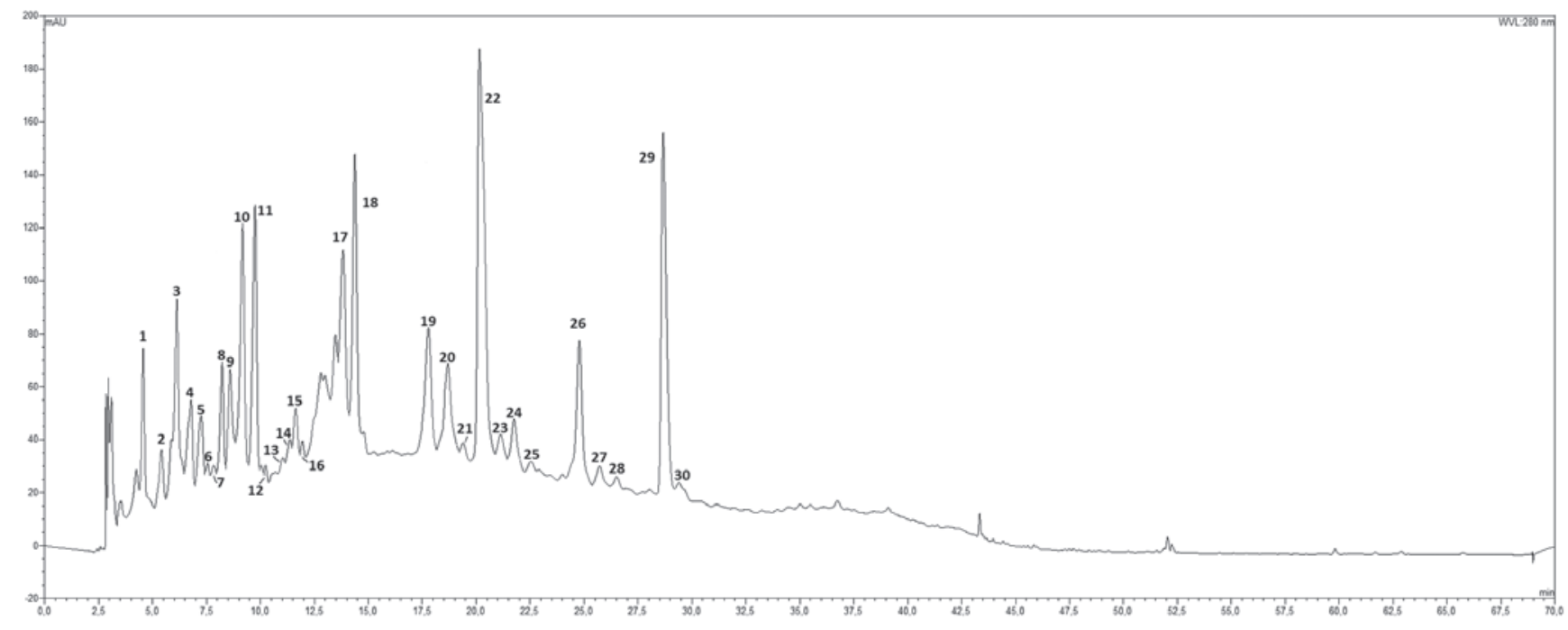

Figure 1. High-performance liquid chromatography-diode array detection analysis of walnut septum extract. Chromatogram, visualized at $280 \mathrm{~nm}$, of the ethanolic extract from the walnut fruit septum. The numbers indicate the 30 different compounds identified.

Bacterial strains. In vitro assays were performed against 32 clinical isolates (16 Gram-positive and $16 \mathrm{Gram}$-negative strains), from the bacterial library of the Department of Biomedical and Biotechnological Sciences (University of Catania, Catania, Italy). Staphylococcus aureus (S. aureus; ATCC 29213), Staphylococcus epidermidis (S. epidermidis; ATCC 14990), Enterococcus faecalis (E. faecalis; ATCC 29212), Enterococcus faecium (E. faecium; ATCC 700221), Escherichia coli (E. coli; ATCC 35218), Pseudomonas aeruginosa (ATCC 27853), Klebsiella pneumoniae (K. pneumoniae; ATCC 700630) and Proteus mirabilis (P. mirabilis; ATCC 7002) were purchased from ATCC and used as reference strains.

Antimicrobial susceptibility testing. The Minimal Inhibitory Concentration (MIC) of J. regia L. extract was tested using the broth microdilution method, with reference to the standard procedures of the Clinical and Laboratory Standards Institute (38). The dry extract was solubilized in ethanol and diluted in cation adjusted Mueller-Hinton broth (CAMHB) (Becton, Dickinson and company) with a 1:100 ratio. The stock solution was filtered using a $0.22 \mu \mathrm{m}$ filter (EMD Millipore) and serial two-fold dilutions were made at concentrations ranging from 0.53 to $275.00 \mu \mathrm{g} / \mathrm{ml}$ in sterile 96 -well microplates (Corning, Inc.) containing CAMHB. Isolated colonies on Mueller Hinton agar plates were suspended in $0.85 \%$ sodium chloride, to achieve a turbidity equivalent to $0.5 \mathrm{McF}$ arland Standard. Turbidity evaluation was performed using a spectrophotometer, at $600 \mathrm{~nm}$ (Synergy 2-BioTek; Agilent Technologies, Inc.). After a dilution with a 1:100 ratio, bacterial suspensions were added to each well for a final concentration of $5 \times 10^{5}$ colony forming units $/ \mathrm{ml}$. The MIC was defined as the lowest concentration at which there was no visible growth following incubation at $37^{\circ} \mathrm{C}$ without $\mathrm{CO}_{2}$ for 18-24 h (39). The broad-spectrum antibiotic ciprofloxacin (Sigma-Aldrich; Merck KGaA), at concentrations ranging from 0.06 to $32.00 \mu \mathrm{g} / \mathrm{ml}$, was used as an antibacterial positive control. Each test included a positive growth control and a negative sterility control (culture broth without bacteria). Results are expressed as the mean form 4 experiments.

PASS analysis. PASS is an online platform for the prediction of biological and pharmacological effects, based on the structure of drug-like compounds (40-42). The analysis also hypothesizes a possible mechanism of action of the studied molecules. Based on this potential, a PASS analysis on HPLC detected compounds, available on the PubChem platform, was performed (43). For each molecule, the Pa (probable activity) and $\mathrm{Pi}$ (probable inactivity) values, both ranging from 0,000 to 1,000 , were reported. Higher values of $\mathrm{Pa}$ are associated with a higher probability to obtain that effect experimentally, although some real activities could be lost (44). The study reported only the cytostatic, cytotoxic and antimicrobial activities of the selected compounds, with a $\mathrm{Pa}>0,700$.

Statistical analysis. Data are expressed as the mean \pm standard deviation of three independent experiments, performed in triplicate. Statistical significance between two groups was analyzed using an unpaired Student's t-test. One-way analysis of variance (ANOVA), followed by Tukey's post-hoc test, was used to compare the means for multiple groups.

\section{Results}

Polyphenol profile and content of Sicilian walnut (J. regia) fruit septum. To characterize the phenolic profile and content of the fruit septum from Sicilian walnuts, a series of HPLC/Uv-vis-DAD and HPLC/ESI-MS analyses was performed and the corresponding DAD chromatogram, visualized at $280 \mathrm{~nm}$, is depicted in Fig. 1. A total of 30 peaks were tentatively identified, in the range between 0 and 30 minutes; identification was made on the basis of their relative retention times, UV-visible (UV-vis) and mass spectral data (data not shown). Injection with pure analytical standards was used when available and comparison with literature data on similar matrices corroborated the assignments from a preliminary analysis. The majority of the 


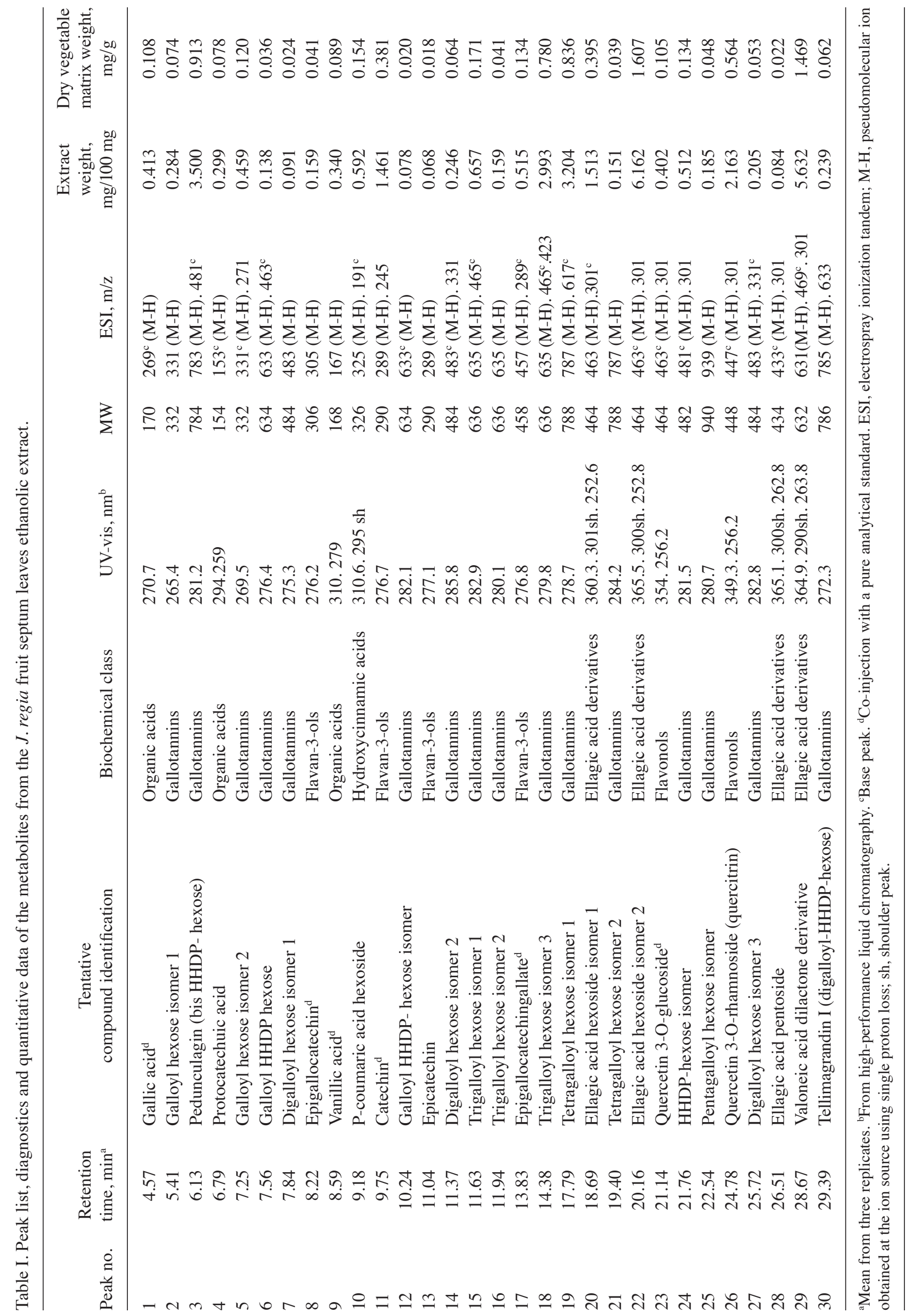


A

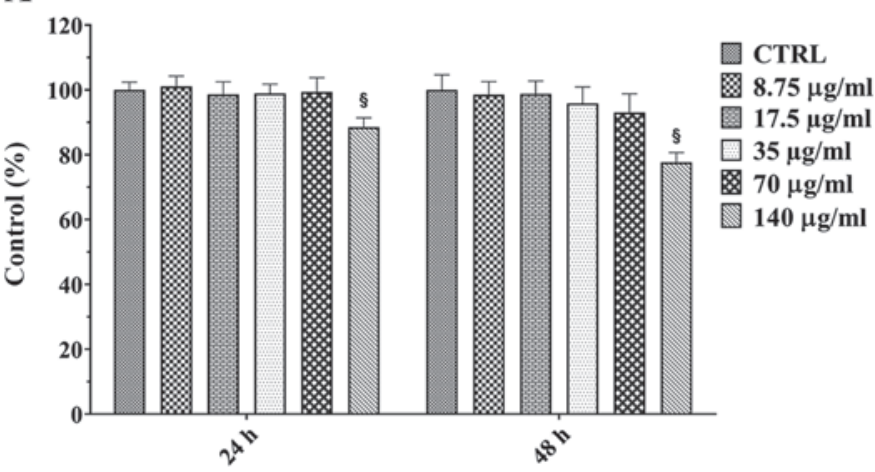

B

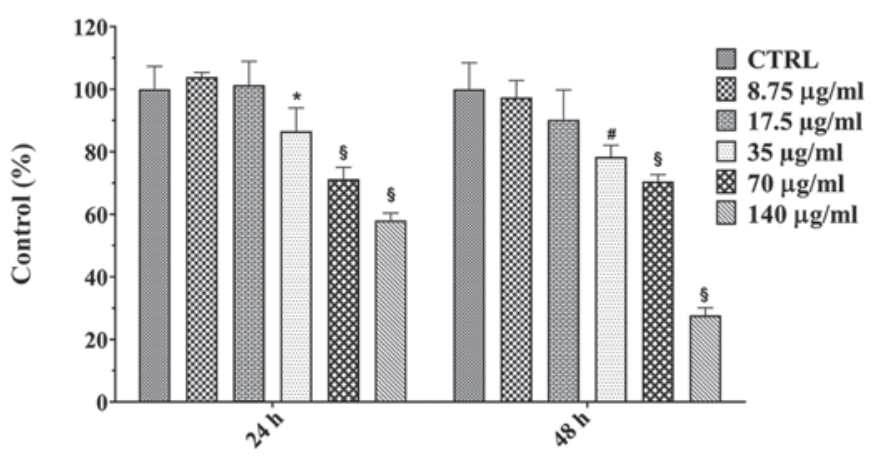

Figure 2. Dose-dependent and time course effects of walnut septum extract on (A) HFF-1 and (B) A172 cell viability. Cells were cultured in culture medium, in the presence or absence of different concentrations of walnut septum extract (range, 8.75 to $140 \mu \mathrm{g} / \mathrm{ml}$ ), for 24 and $48 \mathrm{~h}$. The data are presented as the mean \pm SD from three independent experiments performed in triplicate. Statistically significant differences were determined using one-way analysis of variance ANOVA and Tukey's post hoc test. ${ }^{\circledR} \mathrm{P}<0.0001,{ }^{\sharp} \mathrm{P}<0.001,{ }^{*} \mathrm{P}<0.05$, vs. control at the same incubation time. CTRL, control.
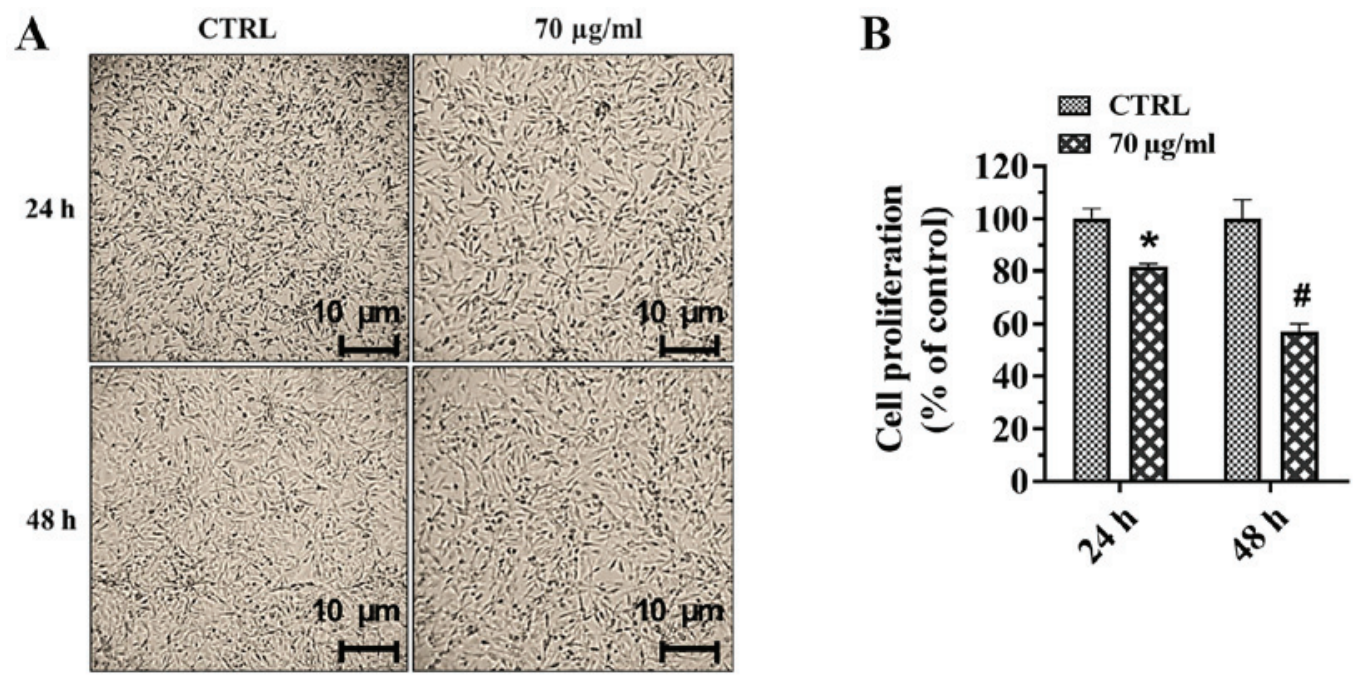

Figure 3. Effect of walnut septum extract on A172 cell proliferation. (A) Representative micrographs (magnification, x100) and (B) quantitative analysis of A172 cells cultured in the presence or absence of $70 \mu \mathrm{g} / \mathrm{ml}$ walnut septum extract for 24 and 48 h. The data are presented as the mean \pm SD from three independent experiments performed in triplicate. Statistically significant differences were determined using independent Student's $\mathrm{t}$-test. ${ }^{\#} \mathrm{P}<0.001$, ${ }^{*} \mathrm{P}<0.05$ versus control at the same incubation time.

thirty peaks showed an UV-vis spectrum with a single peak in the range between 265 and $280 \mathrm{~nm}$ (Table I), which was attributed to gallic acid-based metabolites. Mass spectra analyses, particularly extracted ion chromatograms provided a pivotal contribution in the tentative identification of these peaks. Furthermore, the UV-vis and mass spectral data show a series of mono, di-, tri-, tetra- and penta-galloyl-hexose isomers (Fig. S1), among which pedunculagine, peak number 3 (p.n. 3) and tellimagradine I (p.n. 30) were found. The p.ns. 8,11 and 13 were identified using the corresponding available commercial standards, such as epigallocatechin, catechin and epicatechin, respectively; mass spectra analyses confirmed the attribution. The p.ns. 4 and 9 exhibited a strange UV-vis spectra (two bands at 292 and $255 \mathrm{~nm}$ ), which is typical of catechol chromophore; commercial reference and mass analyses also assisted with identification, which was found to be protocatechuic acid (p.n. 4) and vanillic acid (p.n. 9). The p.n. 10 was identified as the sole detecTable hydroxycinnamic acid present in the extract and reported as p-coumaric acid hexoside from its UV-vis and mass spectra data. The p.ns. 23 and 26 showed a UV-vis spectra (absorptions at 255 and $350 \mathrm{~nm}$; strange spectrum shape) that was similar to quercetin derivatives; following mass analyses these peaks were identified as quercetin 3-O-glucoside (p.n. 23) and quercitrin (quercetin 3-O-rhamnoside; p.n. 26). Another common constituent of the hydrolysable tannins group, ellagic acid, itself is derived from the intramolecular lactonization of HHDP, which confers to this molecule a strange shaped UV-vis spectrum with two absorption bands at 255 and 263-264 $\mathrm{nm}$. This allowed the identification of peaks 20, 22 and 28 to be determined as ellagic acid derivatives; mass spectral data confirmed the attribution as two ellagic acid hexoside isomers (p.ns. 20 and 22) and ellagic acid pentoside (p.n. 28). The p.n. 29 showed a UV-vis spectrum, which was very similar to that of ellagic acid; however, it was not identical, with a more intense peak at $290 \mathrm{~nm}$ (Fig. S2). A literature search on a walnut seed $(45,46)$ or similar seeds (47) identified the compound at p.n. 29 as a 
A

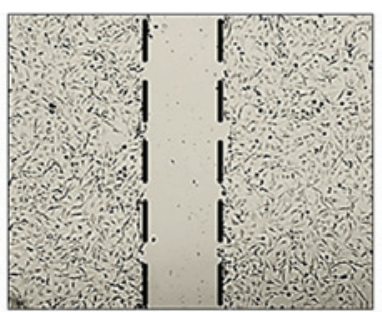

$70 \mu \mathrm{g} / \mathrm{ml}$ to

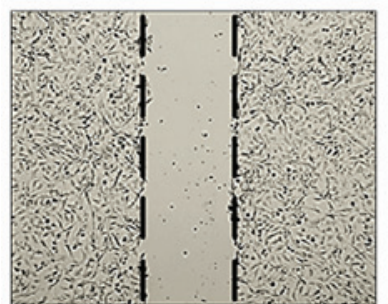

CTRL 24 h

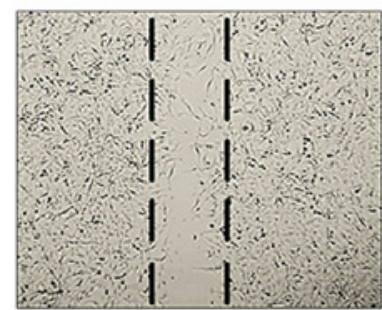

$70 \mu \mathrm{g} / \mathrm{ml} 24 \mathrm{~h}$

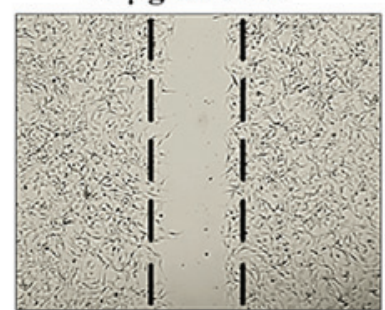

CTRL 48 h

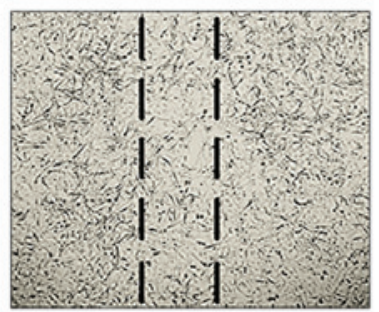

$70 \mu \mathrm{g} / \mathrm{ml} 48 \mathrm{~h}$

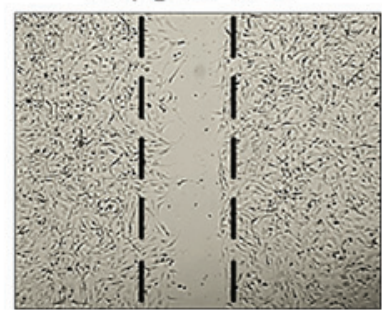

B

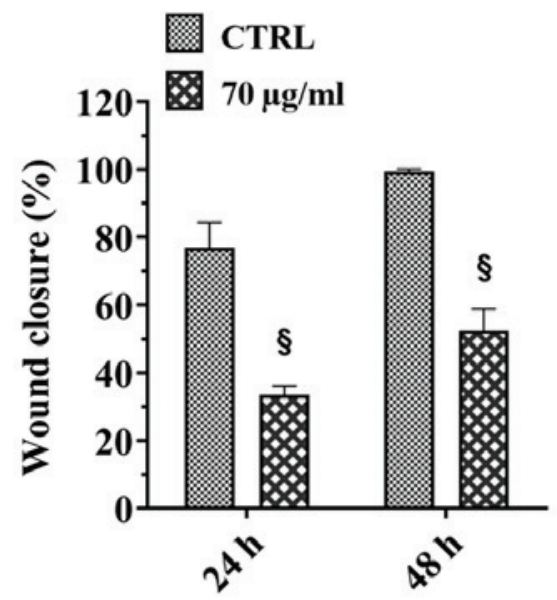

Figure 4. Effect of walnut septum extract on A172 cell migration. A172 cells were cultured in the presence or absence of $70 \mu \mathrm{g} / \mathrm{ml}$ walnut septum extract. (A) Representative images of A172 cells are shown at 0, 24 and $48 \mathrm{~h}$ following creation of the wound and the results were (B) quantified (percent wound closure vs. time). The data are presented as the mean $\pm \mathrm{SD}$, from three independent experiments, performed in triplicate. Statistically significant differences were determined using independent Student's t-test. ${ }^{\#} \mathrm{P}<0.001$ versus control at the same incubation time. CTRL, control.

valoneic acid dilactone derivative (molecular weight, 632). With respect to quantitative analysis, the primary compound in the extract was at peak 22 (ellagic acid hexoside isomer 2; $6.16 \mathrm{mg} / 100 \mathrm{mg}$ extract) followed by valoneic acid dilactone with $5.63 \mathrm{mg} / 100 \mathrm{mg}$ extract and gallotannin pedunculagin 3 with $3.50 \mathrm{mg} / 100 \mathrm{mg}$ extract (Table I). Despite the lower number of compounds with respect to gallotannins, ellagic acid derivatives account for ca. $50 \%$ of the total metabolites in the extract (13.39 mg vs. $32.9 \mathrm{mg}$; Table I), with total gallotannins accounting for $13.51 \mathrm{mg} / 100 \mathrm{mg}$ extract. Flavonoids are the third more represented subclass of polyphenols with only 2.56 total $\mathrm{mg} / 100 \mathrm{mg}$ extract.

Viability of HFF-1 and A172 cells, cultured in the presence of increasing concentrations of walnut septum extract. Prior to investigating the anti-proliferative effect of the natural extract on human A172 glioblastoma cells, the possible cytotoxic effect of the extract on A172 cells and a non-cancerous cell line (HFF-1) was performed using MTT assay. The A172 and HFF-1 cell lines were cultured in absence (control cells) or in presence of increasing concentrations of walnut septum extract, ranging from 8.75 to $140 \mu \mathrm{g} / \mathrm{ml}$, for 24 and $48 \mathrm{~h}$ (Fig. 2A and B). The natural extract was solubilized in ethanol and, subsequently, diluted in medium at $0.05 \%$ final concentration. The treatment with vehicle alone (ethanol) did not cause any change in viability in both cell lines, at the two time points (data not shown). A significant reduction of HFF-1 cell viability occurred only in presence of the highest concentration of the extract $(140 \mu \mathrm{g} / \mathrm{ml})$, at 24 , as well as $48 \mathrm{~h}$ (Fig. 2A). In A172 cells the treatment with lower doses of the natural extract $(8.75$ and $17.5 \mu \mathrm{g} / \mathrm{ml})$ did not produce any effect on cell viability, at both 24 and 48 h. However, a dose-dependent reduction in cell viability was observed when A172 cells were treated with higher doses (from 35 to $140 \mu \mathrm{g} / \mathrm{ml}$ ) of the walnut septum extract (Fig. 2B). The concentration of $70 \mu \mathrm{g} / \mathrm{ml}$, inducing a significant reduction

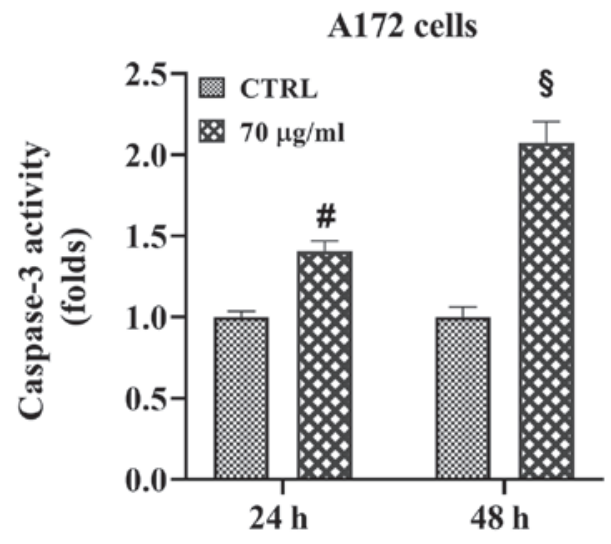

Figure 5. Effect of walnut septum extract on caspase-3 activity in A172 cells. A172 cells were cultured in the presence or absence of $70 \mu \mathrm{g} / \mathrm{ml}$ walnut septum extract, for 24 and 48 h. Caspase-3 activity was determined using a colorimetric protease assay. The data are presented as the mean \pm SD from three independent experiments, performed in triplicate. Statistically significant differences were determined using independent Student's t-test. ${ }^{\S} \mathrm{P}<0.0001$, ${ }^{\#} \mathrm{P}<0.001$ versus control at the same incubation time. CTRL, control.

of A172 cell viability, without affecting HFF-1 cell viability, was selected for subsequent experiments on human glioblastoma cells.

Effect of walnut septum extract on A172 cell proliferation. Proliferation of A172 cells, cultured in the presence or absence of walnut septum extract $(70 \mu \mathrm{g} / \mathrm{ml})$, for 24 and $48 \mathrm{~h}$ was evaluated using a crystal violet assay and the cell micrographs of control and treated cells are shown in Fig. 3A. The quantification of proliferation following crystal violet staining assay demonstrated that the treatment with the natural extract significantly reduced A172 cell proliferation by 20 and $42 \%$ at 24 and $48 \mathrm{~h}$, respectively, compared with that in the control group (Fig. 3B). 
A 1 CTRL 24 h

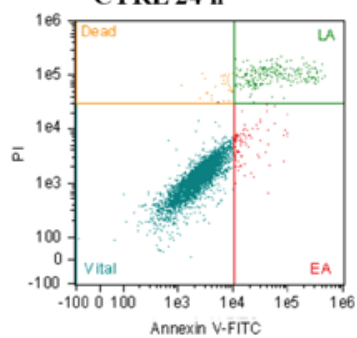

2

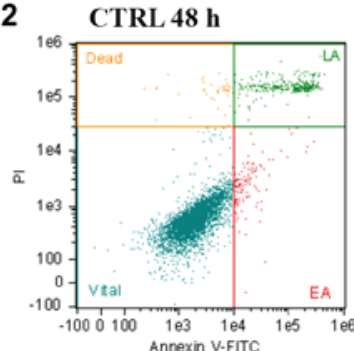

3

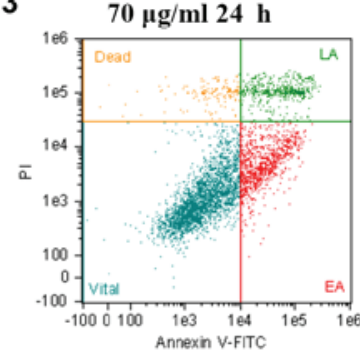

4

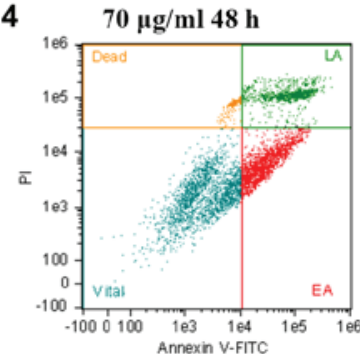

B

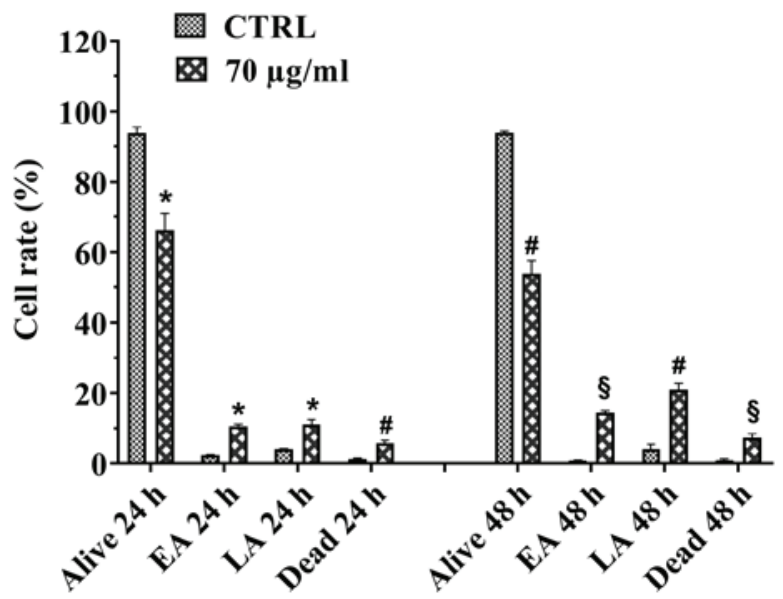

Figure 6. Pro-apoptotic effect of walnut septum extract on A172 cells using a flow cytometry assay. The A172 cells were cultured in the presence or absence of $70 \mu \mathrm{g} / \mathrm{ml}$ walnut septum extract, for 24 and $48 \mathrm{~h}$. (A) Flow cytometry plots and (B) quantification of the results. The data are presented as the mean \pm SD from three independent experiments, performed in triplicate. Statistically significant differences were determined using independent Student's t-test. ${ }^{\circledR} \mathrm{P}<0.0001$, ${ }^{\text {"P }} \mathrm{P}<0.001,{ }^{\text {P }} \mathrm{P}<0.05$ versus control at the same incubation time. EA, early apoptosis; LA late apoptosis; CTRL, control.

Effect of walnut septum extract on A172 cell migration. A172 cell migration was investigated using the wound-healing assay. The migration of cells was monitored for 24 and $48 \mathrm{~h}$ following creation of the wound and the representative images at 0,24 and $48 \mathrm{~h}$ time points are shown in Fig. 4A. The untreated A172 cells were able to migrate across the wound and close it at $48 \mathrm{~h}$. Conversely, the treatment of cells with $70 \mu \mathrm{g}$ walnut septum extract significantly reduced migration of the cells, at 24 and $48 \mathrm{~h}$, compared with that in untreated cells. The results were analyzed quantitatively, and cell migration was significantly decreased by $42 \%$ at $24 \mathrm{~h}$ and by $50 \%$ at $48 \mathrm{~h}$ in cells treated with walnut septum extract, compared with that in the control groups (Fig. 4B).

Effect of walnut septum extract on A172 cell apoptosis. The caspase-3 assay was performed on the human A172 glioblastoma cell line to investigate the ability of walnut septum extract to induce apoptotic death (Fig. 5). A172 cells were cultured in the presence or absence of $70 \mu \mathrm{g} / \mathrm{ml}$ walnut septum extract, for 24 and $48 \mathrm{~h}$. A significant induction in caspase- 3 activity was found in the presence of $70 \mu \mathrm{g} / \mathrm{ml}$ walnut extract compared with that in untreated cells, at both time points. Notably, at the 48-h time point, the activity of the enzyme was double that in A172 treated cells compared with that in the control group.

To further analyze the pro-apoptotic effect of walnut septum extract on the human A172 glioblastoma cell line, flow cytometry evaluation of Annexin-V/PI staining was performed (Fig. 6A and B). The flow cytometry plots are displayed, for each experimental condition, and the distribution of A172 cells in four different quadrants, depending on their staining with Annexin-V and PI (Fig. 6A). A172 cells, cultured without walnut septum extract for 24 and $48 \mathrm{~h}$, were double negative for staining (Annexin-V and PI), therefore are considered as healthy (Fig. 6A, panels 1 and 2). The analysis revealed that treatment with $70 \mu \mathrm{g} / \mathrm{ml}$ walnut septum extract at both 24 and $48 \mathrm{~h}$ increased early and late apoptosis of A172 cells
(Fig. 6A, panels 3 and 4). There was a moderate increase in the number of necrotic cells observed in A172 cells cultured in the presence of $70 \mu \mathrm{g} / \mathrm{ml}$ walnut septum extract (Fig. 6A, panels 3 and 4) compared with that in the control group, at 24 and $48 \mathrm{~h}$ (Fig. 6A, panels 1 and 2). The percentages of the single cell subpopulation (healthy, early apoptotic, late apoptotic and necrotic cells), for each experimental condition, are shown in Fig. 6B. The treatment of A172 cells with $70 \mu \mathrm{g} / \mathrm{ml}$ walnut septum extract caused a significant reduction of healthy cells, followed by a concomitant increment of apoptotic and necrotic cells, which was more evident at $48 \mathrm{~h}$. Notably, the increase in late apoptotic cells cultured with walnut septum extract at $48 \mathrm{~h}$ was higher compared with that in cells at $24 \mathrm{~h}$. The results suggested that, at $70 \mu \mathrm{g} / \mathrm{ml}$, the natural extract could cause apoptotic death of human glioblastoma cells.

Antibacterial activity of walnut septum extract. The antibacterial activity of walnut septum extract was also determined using the standard broad-spectrum drug, ciprofloxacin (Table II). The natural extract exhibited an antibacterial effect on Gram-positive bacteria; however, the effect was found at varying degrees. The MICs were in the ranges of 8.59-275 $\mu \mathrm{g} / \mathrm{ml}$ against $S$. aureus, S. epidermidis, E. faecalis and $E$. faecium. Gram-negative strains were the least sensitive, with MIC values of $275 \mu \mathrm{g} / \mathrm{ml}$ against $E$. coli, K. pneumoniae, $P$. aeruginosa and $P$. mirabilis. The extract was more effective against $P$. aeruginosa compared with that in other Gram-negative bacterial strains (MIC $137.5 \mu \mathrm{g} / \mathrm{ml}$ ).

Furthermore, treatment with the highest doses of natural extract $(275 \mu \mathrm{g} / \mathrm{ml})$ was able to affect the growth of Gram-positive and Gram-negative bacterial strains, most of which were resistant to the antibiotic Ciprofloxacin.

Predicted cytostatic, cytotoxic and antimicrobial activity of walnut septum extract: PASS analysis. To determine which 
Table II. Antimicrobial activity of Juglans regia L. against Gram-positive and Gram-negative bacterial strains .

A, Gram-positive bacterial strains

\begin{tabular}{|c|c|c|c|c|c|}
\hline \multirow[b]{2}{*}{ Strain no. ${ }^{a}$} & \multirow[b]{2}{*}{ Name } & \multirow[b]{2}{*}{ Source } & \multicolumn{2}{|c|}{$\mathrm{MIC}, \mu \mathrm{g} / \mathrm{ml}$} & \multirow[b]{2}{*}{$\mathrm{IC}^{\mathrm{b}}$} \\
\hline & & & Juglans regia $L$. & Cip & \\
\hline $001 / 040$ & S. aureus ATCC 29213 & Standard & 68.75 & 0.50 & $\mathrm{~S}$ \\
\hline $002 / 040$ & S.aureus & Endophtalmitis & 17.18 & 0.25 & $\mathrm{~S}$ \\
\hline 003/040 & S.aureus & Pneumonia & 275.00 & 4.00 & $\mathrm{R}$ \\
\hline $004 / 040$ & S.aureus & Pneumonia & 8.59 & 0.25 & $\mathrm{~S}$ \\
\hline $005 / 040$ & S.aureus & Endophtalmitis & 17.18 & 0.50 & $\mathrm{~S}$ \\
\hline 006/040 & S. epidermidis ATCC 14990 & Standard & 8.59 & 0.12 & $\mathrm{~S}$ \\
\hline 007/040 & S.epidermidis & Osteomyelitis & 8.59 & 0.03 & $\mathrm{~S}$ \\
\hline 008/040 & S.epidermidis & Septicemia & $\mathrm{ORC}$ & 8.00 & $\mathrm{R}$ \\
\hline 009/040 & S.epidermidis & Endophtalmitis & 68.75 & 0.01 & $\mathrm{~S}$ \\
\hline $010 / 040$ & S.epidermidis & Septicemia & 275.00 & 8.00 & $\mathrm{R}$ \\
\hline $011 / 040$ & E. faecalis ATCC 29212 & Standard & 34.37 & 0.50 & $\mathrm{~S}$ \\
\hline $012 / 040$ & E.faecalis & Abscess & 8.59 & 0.50 & $\mathrm{~S}$ \\
\hline 013/040 & E.faecalis & Septicemia & 34.37 & 0.50 & $\mathrm{~S}$ \\
\hline $014 / 040$ & E.faecalis & Pneumonia & 34.37 & 1.00 & $\mathrm{~S}$ \\
\hline $015 / 040$ & E.faecalis & Abscess & 17.18 & 0.25 & $\mathrm{~S}$ \\
\hline $016 / 040$ & E. faecium ATCC 700221 & Standard & $\mathrm{ORC}$ & ORC & $\mathrm{R}$ \\
\hline $017 / 040$ & E.faecium & Cholecystitis & ORC & ORC & $\mathrm{R}$ \\
\hline $018 / 040$ & E.faecium & Catheter cystitis & 275.00 & 8.00 & $\mathrm{R}$ \\
\hline $019 / 040$ & E.faecium & Catheter cystitis & 8.59 & 1.00 & $\mathrm{~S}$ \\
\hline $020 / 040$ & E.faecium & Cholecystitis & 275.00 & 16.00 & $\mathrm{R}$ \\
\hline
\end{tabular}

B, Gram-negative bacterial strains

\begin{tabular}{|c|c|c|c|c|c|}
\hline \multirow[b]{2}{*}{ Strain no. ${ }^{\text {a }}$} & \multirow[b]{2}{*}{ Name } & \multirow[b]{2}{*}{ Source } & \multicolumn{2}{|c|}{$\mathrm{MIC}, \mu \mathrm{g} / \mathrm{ml}$} & \multirow[b]{2}{*}{$\mathrm{IC}^{\mathrm{b}}$} \\
\hline & & & Juglans regia $L$. & Cip & \\
\hline $021 / 040$ & E. coli ATCC 35218 & Standard & 275.00 & 0.01 & $\mathrm{~S}$ \\
\hline $022 / 040$ & E. coli & Septicemia & 275.00 & 0.01 & $\mathrm{~S}$ \\
\hline $023 / 040$ & E. coli & Septicemia & ORC & ORC & $\mathrm{R}$ \\
\hline $024 / 040$ & E. coli & Cystitis & 275.00 & 4.00 & $\mathrm{R}$ \\
\hline $025 / 040$ & E. coli & Cystitis & 275.00 & 8.00 & $\mathrm{R}$ \\
\hline $026 / 040$ & P. aeruginosa ATCC 27853 & Standard & 275.00 & 0.25 & $\mathrm{~S}$ \\
\hline $027 / 040$ & P. aeruginosa & Septicemia & 137.50 & 0.06 & $\mathrm{~S}$ \\
\hline 028/040 & P. aeruginosa & Septicemia & 275.00 & 4.00 & $\mathrm{R}$ \\
\hline $029 / 040$ & P. aeruginosa & Pneumonia & 275.00 & 0.12 & $\mathrm{~S}$ \\
\hline $030 / 040$ & P. aeruginosa & Pneumonia & 275.00 & 16.00 & $\mathrm{R}$ \\
\hline $031 / 040$ & K. pneumoniae ATCC 700630 & Standard & 275.00 & 0.25 & $\mathrm{~S}$ \\
\hline $032 / 040$ & K. pneumoniae & Nephritis & ORC & 4.00 & $\mathrm{R}$ \\
\hline $033 / 040$ & K.pneumoniae & Pneumonia & ORC & 32.00 & $\mathrm{R}$ \\
\hline $034 / 040$ & K.pneumoniae & Pneumonia & ORC & 8.00 & $\mathrm{R}$ \\
\hline $035 / 040$ & K.pneumoniae & Nephritis & 275 & 4.00 & $\mathrm{R}$ \\
\hline $036 / 040$ & P. mirabilis ATCC 7002 & Standard & 275 & 0.25 & $\mathrm{~S}$ \\
\hline $037 / 040$ & P. mirabilis & Cystitis & ORC & 1.00 & $\mathrm{~S}$ \\
\hline $038 / 040$ & P. mirabilis & Cystitis & 275.00 & 0.01 & $\mathrm{~S}$ \\
\hline $039 / 040$ & P. mirabilis & Cystitis & 275.00 & 0.01 & $\mathrm{~S}$ \\
\hline $040 / 040$ & P. mirabilis & Cystitis & ORC & 8.00 & $\mathrm{R}$ \\
\hline
\end{tabular}

anternal directory for bacteria. ${ }^{\mathrm{b}} \mathrm{IC}$ for Cip (Performance standard, Clinical and Laboratory Standards Institute no. M100-S27): $\leq 1, \mathrm{~S} ; 2$, I; $\geq 4$, R. Cip, ciprofloxacin; IC, interpretive criteria; S, susceptible; I, intermediate; R, resistant; ORC, out range of concentration; S. aureus, Staphylococcus aureus; S. epidermidis, Staphylococcus epidermidis; E. faecalis, Enterococcus faecalis; E. faecium, Enterococcus faecium; E. coli, Escherichia coli; P. aeruginosa, Pseudomonas aeruginosa; K. pneumoniae, Klebsiella pneumoniae; P. mirabilis, Proteus mirabilis; ATCC, American Tissue Culture Collection. 
molecules could be responsible for the biological effects of walnut septum extract, PASS analysis was performed. The PubChem platform was used to verify the predicted activities of HPLC identified compounds (43). The results showed an activity spectrum for each molecule, including antineoplastic, antimutagenic, cytostatic, anti-infective, and antiseptic effects (Table III).

\section{Discussion}

Increasing scientific evidence highlights the crucial role of diet (48), probiotics (49) and nutraceutical (50) products on biological processes (pathogen resistance, xenobiotic and drug metabolism, delay in the aging process, prevention of chronic diseases, increase in life expectancy, or support in the structure or function of the body) and, consequently, on human health and diseases, including cancer (51-55).

Notably, bad dietary and lifestyle habits can induce both genetic and epigenetic changes (for example, DNA methylation, histone post-translational modification, such as acetylation, ubiquitination, sumoylation, phosphorylation and ADP-ribosylation) (56), which can significantly impact the health status of individuals, inducing genetic mutations or the alteration in the expression levels of micro(mi)RNAs, which are known to be involved in the pathogenesis of different tumors. For example, upregulation (such as hsa-miR-196a-5p, hsa-miR-503-5p, hsa-miR-7-5p, hsa-miR-542-5p, hsa-miR-142-5p, hsa-miR-19a-3p, hsa-miR-18a-5p, hsa-miR-19b-3p, hsa-miR-32-5p, hsa-miR-196b-5p, hsa-miR-33b-5p, hsa-miR-34b-3p, from 1.55 to 8.1 fold change) and downregulation (such as hsa-miR-195-5p, hsa-miR-378a-5p, hsa-miR-363-3p, hsa-miR-100-5p, hsa-miR-328-5p, hsa-miR-99a-5p, hsa-miR-218-5p, hsa-miR-432-5p, hsa-miR-379-5p, hsa-miR-154-5p, hsa-miR-133a-3p, hsa-miR-487b-5p, hsa-miR-135a-5p, hsa-miR-411-5p hsa-miR-1-3p) of miRNAs have been demonstrated in oral cancers. Furthermore, hsa-miR514a-3p, hsa-miR-508-3p, hsa-miR-509-3-5p, hsa-miR-513c-5p, hsa-miR-513a-5p were downregulated, while hsa-miR-592 and hsa-miR-199a-5p were upregulated in patients with high-grade human melanoma compared with that in patients with low-grade disease (57-60). On the other hand, it has been widely demonstrated that some micro- and macronutrients, including those contained in walnuts, have beneficial effects for individuals. In particular, it has been demonstrated that the consumption of $18 \%$ of dietary calories from walnuts significantly reduced the growth rate of MDA-MB 231 human breast cancer cells implanted in mice (61). Another study demonstrated that walnut consumption also prevented cancer development in a transgenic mouse genetically programmed to develop cancer (62). The effects on cancer suppression were associated with the walnut content of phenolic compounds, which could be distinguished into flavonoids, phenolic acids, stilbenes, coumarins, lignans, and tannins (63). Active molecules are used in Traditional Chinese Medicine, Ayurveda, Kampo, Traditional Korean Medicine, and in Unani (2). Over the last ten years the number of reports focusing on the biological activity of natural extracts has increased. Among the biological properties, the antiproliferative and antimicrobial effect of natural extracts have been widely reported (64-68). Walnut extracts exerted a potent anticancer effect against different cancer cell lines, such as human colorectal adenocarcinoma, breast cancer and oral squamous carcinoma cancer (69). In particular, the dose-dependent antiproliferative effect of walnut septum extract on human A549 lung adenocarcinoma, human T47D-KBluc and MCF-7 breast cancer cell lines has been demonstrated (70). In addition, walnut consumption or walnut extracts showed antioxidant, anti-inflammatory and antiaging properties in the brain $(26,29,32)$. However, the antitumor activity of walnut septum extract against one of the most aggressive brain tumors, glioblastoma, has not been investigated.

In the present study, the chemical composition of the septum extract of Sicilian walnuts was analyzed. Walnuts are considered as a type of 'superfood', with high nutritional content, as they contain numerous essential unsaturated fatty acids, tocopherols, sterols, fiber and polyphenols. With respect to biosynthesis, the majority of the known hydrolysable tannins originate from the different coupling possibilities of the same few building blocks: gallic acid, its dimer hexahydroxydiphenyl HHDP (sharing a similar chromophore) and a polyol, usually glucose or quinic acid (45). Walnut polyphenols comprise several subclasses of molecules, including flavan-3-ols, flavonols and hydrolizable tannins, which have been reported to dominate the phenolic profile of J. regia fruit $(45,46,71)$. With respect to the walnut fruit septum (the wooden diaphragm inside the kernel), it has been used for a long time as a folk remedy in Traditional Chinese Medicine, with the name of Diaphragma juglandis fructus (72); however, there have been few studies investigating the compounds inside. A recent study by Li et al (73), bridged this gap by reporting a detailed characterization of phenols present in the walnut fruit septum from a Chinese cultivar using ultra performance liquid chromatography-MS analyses; the authors found 75 different compounds, including flavonoids (flavan-3-ols and flavanols), ellagic acid derivatives and gallotannins, thus confirming the precise compositional similarity of this part with the corresponding fruit (45).

The results of the chemical analysis in the present study are similar to those reported by previous studies $(45,73)$, with polyphenols being the majority type of metabolites found in walnut by-products and hydrolyzable tannins are the most abundant polyphenol subclass. The presence of a valoneic acid dilactone derivative in considerable amounts in the extract in the present study was in disagreement with the study by Li et al (73), which reported several ellagic acid derivatives but not valoneic acid.

Furthermore, Li et al (73) identified the presence of several hydroxycinnamic acids and 11 different quercetin derivatives, whereas the presence of p-coumaric hexoside and glucoside and rhamnoside derivatives were found in the present study. These discrepancies could be due to both the different provenance of the plant material and to the different extraction solvent used. Notably, a high content of gallotannins, ellagic acid derivatives and flavanols were identified which have been associated with different biological proprieties, including cytostatic and antimicrobial activities (74-76).

Based on the chemical analysis, the cytostatic and cytotoxic effects of walnut septum extract on the human A172 glioblastoma cell line was investigated. The treatment of A172 cells with walnut septum extract resulted in a significant reduction of their viability, in a dose-dependent manner. Notably, only the highest dose of the extract was able to reduce the viability 
Table III. Prediction of Activity Spectra for Substances analysis for walnut septum extract.

\begin{tabular}{|c|c|c|c|c|}
\hline Peak no. & Compound & $\begin{array}{l}\text { Probable } \\
\text { activity }\end{array}$ & $\begin{array}{l}\text { Probable } \\
\text { inactivity }\end{array}$ & $\begin{array}{c}\text { Predicted } \\
\text { biological activity }\end{array}$ \\
\hline 1 & Gallic acid & 0.828 & 0.005 & Anti-infective \\
\hline 3 & $\begin{array}{l}\text { Pedunculagin } \\
\text { (bis HHDP-hexose) }\end{array}$ & $\begin{array}{l}0.918 \\
0.860 \\
0.817 \\
0.898\end{array}$ & $\begin{array}{l}0.005 \\
0.005 \\
0.006 \\
0.005\end{array}$ & $\begin{array}{l}\text { Antineoplastic } \\
\text { Apoptosis agonist } \\
\text { Cytostatic } \\
\text { TP53 expression enhancer }\end{array}$ \\
\hline 4 & Protocatechuic acid & $\begin{array}{l}0.776 \\
0.834 \\
0.906\end{array}$ & $\begin{array}{l}0.005 \\
0.003 \\
0.003\end{array}$ & $\begin{array}{l}\text { Anti-infective } \\
\text { Antimutagenic } \\
\text { Antiseptic }\end{array}$ \\
\hline 8 & Epigallocatechin & $\begin{array}{l}0.815 \\
0.953 \\
0.742 \\
0.712 \\
0.759 \\
0.710 \\
0.963\end{array}$ & $\begin{array}{l}0.005 \\
0.001 \\
0.019 \\
0.005 \\
0.010 \\
0.005 \\
0.003\end{array}$ & $\begin{array}{l}\text { Anticarcinogenic } \\
\text { Antimutagenic } \\
\text { Antineoplastic } \\
\text { Antiviral (Influenza) } \\
\text { Apoptosis agonist } \\
\text { Proliferative diseases treatment } \\
\text { TP53 expression enhancer }\end{array}$ \\
\hline 9 & Vanillic acid & $\begin{array}{l}0.708 \\
0.834 \\
0.898 \\
0.713\end{array}$ & $\begin{array}{l}0.007 \\
0.003 \\
0.003 \\
0.024\end{array}$ & $\begin{array}{l}\text { Anti-infective } \\
\text { Antimutagenic } \\
\text { Antiseptic } \\
\text { TP53 expression enhancer }\end{array}$ \\
\hline 10 & $\begin{array}{l}\text { P-coumaric acid } \\
\text { hexoside }\end{array}$ & $\begin{array}{l}0.887 \\
0.875 \\
0.759 \\
0.751 \\
0.813 \\
0.744 \\
0.955 \\
0.811 \\
0.828\end{array}$ & $\begin{array}{l}0.003 \\
0.004 \\
0.017 \\
0.004 \\
0.005 \\
0.005 \\
0.002 \\
0.003 \\
0.009\end{array}$ & $\begin{array}{l}\text { Anticarcinogenic } \\
\text { Anti-infective } \\
\text { Antineoplastic } \\
\text { Antiviral (Influenza) } \\
\text { Caspase } 3 \text { stimulant } \\
\text { Cell adhesion molecule inhibitor } \\
\text { G-protein-coupled receptor kinase inhibitor } \\
\text { Proliferative diseases treatment } \\
\text { TP53 expression enhancer }\end{array}$ \\
\hline 11 & Catechin & $\begin{array}{l}0.795 \\
0.959\end{array}$ & $\begin{array}{l}0.005 \\
0.003\end{array}$ & $\begin{array}{l}\text { Anticarcinogenic } \\
\text { TP53 expression enhancer }\end{array}$ \\
\hline 13 & Epicatechin & $\begin{array}{l}0.795 \\
0.959\end{array}$ & $\begin{array}{l}0.005 \\
0.003\end{array}$ & $\begin{array}{l}\text { Anticarcinogenic } \\
\text { TP53 expression enhancer }\end{array}$ \\
\hline 17 & Epigallocatechingallate & $\begin{array}{l}0.841 \\
0.926 \\
0.771 \\
0.741 \\
0.937\end{array}$ & $\begin{array}{l}0.004 \\
0.002 \\
0.003 \\
0.012 \\
0.004\end{array}$ & $\begin{array}{l}\text { Anticarcinogenic } \\
\text { Antimutagenic } \\
\text { Antiviral (Influenza) } \\
\text { Apoptosis agonist } \\
\text { TP53 expression enhancer }\end{array}$ \\
\hline 23 & Quercetin 3-O-glucoside & $\begin{array}{l}0.965 \\
0.714 \\
0.726 \\
0.763 \\
0.833 \\
0.715 \\
0.792 \\
0.801 \\
0.825 \\
0.921 \\
0.959\end{array}$ & $\begin{array}{l}0.001 \\
0.009 \\
0.006 \\
0.004 \\
0.008 \\
0.005 \\
0.009 \\
0.005 \\
0.006 \\
0.002 \\
0.003\end{array}$ & $\begin{array}{l}\text { Anticarcinogenic } \\
\text { Antifungal } \\
\text { Anti-infective } \\
\text { Antimutagenic } \\
\text { Antineoplastic } \\
\text { Antiviral (Influenza) } \\
\text { Apoptosis agonist } \\
\text { Caspase } 3 \text { stimulant } \\
\text { Cytostatic } \\
\text { Proliferative diseases treatment } \\
\text { TP53 expression enhancer }\end{array}$ \\
\hline
\end{tabular}


Table III. Continued.

\begin{tabular}{|c|c|c|c|c|}
\hline Peak no. & Compound & $\begin{array}{l}\text { Probable } \\
\text { activity }\end{array}$ & $\begin{array}{l}\text { Probable } \\
\text { inactivity }\end{array}$ & $\begin{array}{c}\text { Predicted } \\
\text { biological activity }\end{array}$ \\
\hline \multirow[t]{9}{*}{26} & \multirow{9}{*}{$\begin{array}{l}\text { Quercetin 3-O-rhamnoside } \\
\text { (quercitrin) }\end{array}$} & 0.943 & 0.002 & Anticarcinogenic \\
\hline & & 0.740 & 0.008 & Antifungal \\
\hline & & 0.748 & 0.005 & Antimutagenic \\
\hline & & 0.854 & 0.007 & Antineoplastic \\
\hline & & 0.814 & 0.007 & Apoptosis agonist \\
\hline & & 0.803 & 0.005 & Caspase 3 stimulant \\
\hline & & 0.751 & 0.008 & Cytostatic \\
\hline & & 0.890 & 0.002 & Proliferative diseases treatment \\
\hline & & 0.928 & 0.004 & TP53 expression enhancer \\
\hline \multirow[t]{2}{*}{30} & Tellimagrandin I & 0.706 & 0.007 & Anti-infective \\
\hline & (digalloyl-HHDP-hexose) & 0.790 & 0.012 & TP53 expression enhancer \\
\hline
\end{tabular}

Only activities with probable activity $>0.700$ and PubChem available compounds are shown. HHDP, hexahydroxydiphenol.

of non-cancerous cells. On the other hand, the viability of A172 cells was affected at the intermedia dose $(35 \mu \mathrm{g} / \mathrm{ml})$. However, since this dose showed a modest effect, $70 \mu \mathrm{g} / \mathrm{ml}$ was chosen for all the experiments. Furthermore, the cytostatic activity was further evaluated using proliferation and migration assays, and the results demonstrated a reduced ability of treated cells to proliferate and migrate compared with that in the control group. The results of the present study are supported by data reporting the cytostatic activity of walnut extracts against different cancer cell lines. For example, the antiproliferative effect of walnut seed, green husk and leaf methanolic extracts on two human renal (A-498 and 769-P) and one colon (Caco2) cancer cell line has been reported (77). However, a concentration of $500 \mu \mathrm{g} / \mathrm{ml}$ of walnut methanolic extracts was used to treat human renal and colon cells, which is much higher compared with that used in in the present study. This could suggest either a higher sensitivity of the human A172 glioblastoma cells compared with that in the human renal and colon cell lines to the extract action, or to a greater activity of walnut septum extract compared to the extracts from other parts of the walnut.

The ability of the walnut septum extract to decrease A172 cell proliferation and migration led to the hypothesis that it could exert a pro-apoptotic action or act against proteases and proteins that favor cell invasion and migration. This has been supported from preliminary animal studies, which found that walnut extracts were effective in reducing the concentration of matrix metalloproteinases at the mRNA and protein level, that are well-known to be involved in tumor invasion (78-80). In the same manner, several studies have demonstrated the pro-apoptotic action of walnut septum polyphenols for example, in human breast cancer cell lines implanted in nude mice, and in mammary gland, prostate, colon, and renal cancers tumors in transgenic mouse models $(62,81)$. The results in the present study revealed that human glioblastoma cells underwent apoptosis, induced by the treatment with natural walnut septum extract. It is well-known that caspase-3 mediates programmed cell death, as it catalyzes the cleavage of numerous key cellular target proteins, such as the DNA repair enzyme poly (ADP-ribose) polymerase, the retinoblastoma protein and the DNA-dependent protein kinase catalytic subunit $(82,83)$. Phytochemical analysis of walnut septum extract revealed the presence of the two flavonoids, epigallocathecin and epigallocathecingallate, both have been found to exhibit antitumor activity in in vivo and in vitro models of human breast cancer (84). Notably, it has also been reported that epigallocathecingallate induced apoptosis of human T98G and U87MG glioblastoma cell lines, but not in human normal astrocytes, by activating the pro-apoptotic caspase 3 protein (85). In the present study, a significant increase in caspase-3 activity was found, following treatment of A172 cells with $70 \mu \mathrm{g} / \mathrm{ml}$ walnut septum extract, which primarily occurred after $48 \mathrm{~h}$. These findings were consistent with the results obtained by flow cytometry analyses, in which there was a significant reduction in the number of healthy cells, followed by a significant increase in the number of apoptotic cells, in A172 treated cells, compared with that in the control group, particularly after $48 \mathrm{~h}$ incubation. In particular, following treatment for $48 \mathrm{~h}$, there was an increase in the number of late apoptotic cells, compared with that at $24 \mathrm{~h}$, indicating that a prolonged treatment period with walnut extract induces an irreversible apoptotic death of glioblastoma cells. The increase in the number of glioblastoma apoptotic cells confirmed the cytotoxic activity of the walnut septum extract against one of the most malignant tumors, for which therapy remains ineffective. Deficiencies in the immune system of patients undergoing chemotherapy determine the reactivation and invasion of latent microorganisms, with an increased risk for patients with cancer of opportunistic infections (25). Microbiological studies demonstrated the ability of different plant extracts to prevent bacterial and fungal growth (1,86-90). For example, in our previous study, the ability of the pellicle extract to inhibit the growth and biofilm formation of 7 coagulase-negative staphylococci strains and to eradicate the biofilm, previously formed by bacteria, was demonstrated (4). The antibacterial activity 
of walnut septum extract against several Gram-positive and Gram-negative bacterial strains was also investigated. The selection of the strains was based on their clinical relevance, being responsible for the most common nosocomial infections and presenting a different spectrum of antibiotic susceptibility (Table II).

Notably, Gram-positive bacteria was found to be more sensitive to the action of walnut septum extract compared with that in Gram-negative bacterial strains, as indicated by the lower MIC values, which could be due to a different cell wall composition and structure of the two types of microorganisms (91). The Gram-positive cell wall is composed of peptidoglycan, teichoic and lipoteichoic acids, while in Gram-negative bacteria it is constituted of a thin layer of peptidoglycan, enveloped by an external membrane containing lipopolysaccharides and lipoproteins (92). This further layer reduces membrane permeability, providing selective movement of molecules, and is known to be responsible for the antibiotic therapy failure in Gram-negative bacteria-related infections (92-95). This could explain the efficacy of the natural extract in reducing the Gram-positive bacteria growth already at low concentrations (from 8.59 to $34.37 \mu \mathrm{g} / \mathrm{ml})$.

However, according to the study by Saraiva et al (96), walnut septum extract was found to be an active antimicrobial agent for S. aureus and P. aeruginosa, as the MIC values ranged from 100 to $500 \mu \mathrm{g} / \mathrm{ml}$.

The biological properties found in the walnut septum extract could be due to the presence of specific active compounds, in which PASS analysis (Table III) predicted cytostatic, cytotoxic and antimicrobial effects. Furthermore, some molecules, such as p-coumaric acid hexoside (p.n. 10) (97), quercetin 3-O-glucoside (p.n. 23) (98), quercetin 3-O-rhamnoside (quercitrin) (p.n. 26) (99) were predicted pro-apoptotic agents by stimulating caspase-3 expression. The compounds [pedunculagin (bis HHDP-hexose) (p.n. 3) (62), epigallocatechin (p.n. 8), epigallocatechingallate (p.n. 17) (85), quercetin 3-O-rhamnoside (quercitrin) (p.n. 26) (100)] were predicted to promote apoptotic death. Therefore, the results highlight a dual role of walnut septum extract, supporting a possible use as a co-adjuvant in glioblastoma treatment, as it is able to counteract both tumor cell proliferation and bacterial growth. These results will pave the way for additional functional and molecular studies to elucidate the molecular mechanisms responsible for the anti-proliferative effects mediated by walnut septum extracts. The development of novel molecular and proteomic high-throughput technologies has enabled the detection of small changes in the expression levels of cancer hallmarks, including DNA, microRNAs, proteins, small molecules (such as cell lipids, metabolites, organic compounds), circulating tumor cells, and extracellular vesicles $(11,101,102)$. Therefore, the administration of nutraceutical compounds coupled with highly sensitive diagnostic and prognostic techniques represents a promising strategy for the management of patients with glioblastoma. Further validation of the data in the present study will be performed in additional different tumor cell lines, including tumor organoids, as well as in a clinical setting.

In conclusion, phytochemical analysis of walnut septum extract revealed a high content of active compounds, such as gallotannins, ellagic acid derivatives and flavanols. Subsequently, the ability of walnut septum extract to reduce cell viability, proliferation and migration in human A172 glioblastoma cell line was found; however, the extract did not affect the viability of the primary human HFF-1 foreskin fibroblast-1 cell line. Furthermore, caspase-3 activity showed a significant increase following incubation for $48 \mathrm{~h}$. The antimicrobial analysis of walnut septum extract highlighted the ability of the extract to counteract bacterial growth, particularly in Gram-positive bacteria. The dual function shown by the walnut septum extract could be due to the presence of a cocktail of biologically active compounds that can alter cell physiology, producing cytostatic, cytotoxic and antibacterial effects, as identified using PASS analysis. The promising results could provide a novel prospective on the possible and future applications of walnut septum extract as co-adjuvant treatment in cancer therapy.

\section{Acknowledgements}

The authors would like to thank Professor Salvatore Ragusa, a botanist at the Department of Health Sciences, Magna Graecia University of Catanzaro (Catania, Italy) for the authentication of the specimens.

\section{Funding}

This research was funded by a National Grant from Ministry of Education, University and Research (grant no. PRIN 2015JXE7E8) and by the Piano triennale per la Ricerca Linea Intervento 2, University of Catania, Italy.

\section{Availability of data and materials}

The data used and/or analyzed during the present study are available from the corresponding author on reasonable request.

\section{Authors' contributions}

CG, MTC, GL, CDA and MS made substantial contributions to the conception and design of the study. FD, CG, APA, LS, LP, GAM acquired, analyzed and interpreted the data. GL, CDA, and MS drafted the article and revised it critically for important intellectual content. All authors read and approved the final manuscript. All authors agree to be held accounTable for all aspects of the work in ensuring that questions related to the accuracy or integrity of the work are appropriately investigated and resolved.

\section{Ethics approval and consent to participate}

Not applicable.

\section{Patient consent for publication}

Not applicable.

\section{Competing interests}

The authors declare that they have no competing interests. 


\section{References}

1. Genovese C, Acquaviva R, Ronsisvalle S, Tempera G, Antonio Malfa G, D'Angeli F, Ragusa S and Nicolosi D: In vitro evaluation of biological activities of Orobanche crenata Forssk. leaves extract. Nat Prod Res: doi:10.1080/14786419.2018.155 2697.

2. Yuan H, Ma Q, Ye L and Piao G: The Traditional medicine and modern medicine from natural products. Molecules 21: 21 , 2016.

3. Jahanban-Esfahlan A, Ostadrahimi A, Tabibiazar M and Amarowicz R: A Comparative review on the extraction, antioxidant content and antioxidant potential of different parts of walnut (Juglans regia L.) fruit and tree. Molecules 24: 24, 2019.

4. Acquaviva R, D'Angeli F, Malfa GA, Ronsisvalle S, Garozzo A, Stivala A, Ragusa S, Nicolosi D, Salmeri M and Genovese C: Antibacterial and anti-biofilm activities of walnut pellicle extract (Juglans regia L.) against coagulase-negative staphylococci. Nat Prod Res: doi:10.1080/14786419.2019.1650352.

5. Britton MTLC, Dandekar AM, McGranahan GH and Caboni E: Persian Walnut. Compendium Transgenic Crop Plants 4 285-300, 2009.

6. Ara I., Shinwari M.M.A., Rashed S.A. and M.A. B: Evaluation of antimicrobial properties of two different extracts of Juglans regia tree bark and search for their compounds using gas chromatohraphy-mass spectrum. International Journal of Biology: doi:10.5539/ijb.v5n2p92.

7. Wei Q, Ma XH and Dong JE: Preparation, chemical constituents and antimicrobial activity of pyroligneous acids from walnut tree branches. J Anal Appl Pyrolysis 87: 24-28, 2010.

8. Rywaniak J, Luzak B, Podsedek A, Dudzinska D, Rozalski M and Watala C: Comparison of cytotoxic and anti-platelet activities of polyphenolic extracts from Arnica montana flowers and Juglans regia husks. Platelets 26: 168-176, 2015.

9. Salimi M, Ardestaniyan MH, Mostafapour Kandelous H, Saeidnia S, Gohari AR, Amanzadeh A, Sanati H, Sepahdar Z, Ghorbani S and Salimi M: Anti-proliferative and apoptotic activities of constituents of chloroform extract of Juglans regia leaves. Cell Prolif 47: 172-179, 2014.

10. Hanif F, Muzaffar K, Perveen K, Malhi SM and Simjee ShU: Glioblastoma multiforme: A review of its epidemiology and pathogenesis through clinical presentation and treatment. Asian Pac J Cancer Prev 18: 3-9, 2017.

11. Silantyev AS, Falzone L, Libra M, Gurina OI, Kardashova KS, Nikolouzakis TK, Nosyrev AE, Sutton CW, Mitsias PD and Tsatsakis A: Current and future trends on diagnosis and prognosis of glioblastoma: From molecular biology to proteomics. Cells 8: 8, 2019.

12. Bray F, Ferlay J, Soerjomataram I, Siegel RL, Torre LA and Jemal A: Global cancer statistics 2018: GLOBOCAN estimates of incidence and mortality worldwide for 36 cancers in 185 countries. CA Cancer J Clin 68: 394-424, 2018.

13. Rock K, McArdle O, Forde P, Dunne M, Fitzpatrick D, O'Neill B and Faul C: A clinical review of treatment outcomes in glioblastoma multiforme--the validation in a non-trial population of the results of a randomised Phase III clinical trial: Has a more radical approach improved survival? Br J Radiol 85: e729-e733, 2012.

14. Motta C, D'Angeli F, Scalia M, Satriano C, Barbagallo D, Naletova I, Anfuso CD, Lupo G and Spina-Purrello V: PJ-34 inhibits PARP-1 expression and ERK phosphorylation in glioma-conditioned brain microvascular endothelial cells. Eur J Pharmacol 761: 55-64, 2015

15. van Tellingen O, Yetkin-Arik B, de Gooijer MC, Wesseling P, Wurdinger $\mathrm{T}$ and de Vries HE: Overcoming the blood-brain tumor barrier for effective glioblastoma treatment. Drug Resist Updat 19: 1-12, 2015.

16. De Matteis V, Rizzello L, Ingrosso C, Liatsi-Douvitsa E, De Giorgi ML, De Matteis G and Rinaldi R: Cultivar-dependent anticancer and antibacterial properties of silver nanoparticles synthesized using leaves of different Olea Europaea trees. Nanomaterials (Basel) 9: 9, 2019.

17. Menzl I, Witalisz-Siepracka A and Sexl V: CDK8-novel therapeutic opportunities. Pharmaceuticals (Basel) 12: 12, 2019.

18. Candido S, Lupo G, Pennisi M, Basile MS, Anfuso CD, Petralia MC, Gattuso G, Vivarelli S, Spandidos DA, Libra M, et al: The analysis of miRNA expression profiling datasets reveals inverse microRNA patterns in glioblastoma and Alzheimer's disease. Oncol Rep 42: 911-922, 2019.
19. Naletova I, Cucci LM, D'Angeli F, Anfuso CD, Magrì A, La Mendola D, Lupo G and Satriano C: A tunable nanoplatform of nanogold functionalised with angiogenin peptides for anti-angiogenic therapy of brain tumours. Cancers (Basel) 11: 11, 2019.

20. Falzone L, Salomone S and Libra M: Evolution of Cancer pharmacological treatments at the turn of the third millennium. Front Pharmacol 9: 1300, 2018.

21. Christofi T, Baritaki S, Falzone L, Libra M and Zaravinos A: Current perspectives in cancer immunotherapy. Cancers (Basel) 11: 11, 2019

22. Abarca-Merlin DM,Maldonado-BernalC and Alvarez-Arellano L: Toll-like receptors as therapeutic targets in central nervous system tumors. BioMed Res Int 2019: 5286358, 2019.

23. Oberheim Bush NA, Hervey-Jumper SL and Berger MS: Management of glioblastoma, present and future. World Neurosurg 131: 328-338, 2019.

24. Stupp R, Dietrich PY, Ostermann Kraljevic S, Pica A, Maillard I, Maeder P, Meuli R, Janzer R, Pizzolato G, Miralbell R, et al: Promising survival for patients with newly diagnosed glioblastoma multiforme treated with concomitant radiation plus temozolomide followed by adjuvant temozolomide. J Clin Oncol 20: 1375-1382, 2002.

25. Taplitz RA, Kennedy EB, Bow EJ, et al: Antimicrobial prophylaxis for adult patients with cancer-related immunosuppression: ASCO and IDSA clinical practice guideline update. J Clin Oncol 36: 3043-3054, 2018.

26. Poulose SM, Bielinski DF and Shukitt-Hale B: Walnut diet reduces accumulation of polyubiquitinated proteins and inflammation in the brain of aged rats. J Nutr Biochem 24: 912-919, 2013.

27. Arab L and Ang A: A cross sectional study of the association between walnut consumption and cognitive function among adult US populations represented in NHANES. J Nutr Health Aging 19: 284-290, 2015.

28. Chauhan A and Chauhan V: Beneficial effects of walnuts on cognition and brain health. Nutrients 12: 12, 2020.

29. Rusu ME, Georgiu C, Pop A, Mocan A, Kiss B, Vostinaru O, Fizesan I, Stefan MG, Gheldiu AM, Mates L, et al: Antioxidant effects of walnut (Juglans regia L.) kernel and walnut septum extract in a D-galactose-induced aging model and in naturally aged rats. Antioxidants 9: 9, 2020.

30. Chauhan N, Wang KC, Wegiel J and Malik MN: Walnut extract inhibits the fibrillization of amyloid beta-protein, and also defibrillizes its preformed fibrils. Curr Alzheimer Res 1: 183-188, 2004.

31. Muthaiyah B, Essa MM, Chauhan V and Chauhan A: Protective effects of walnut extract against amyloid beta peptide-induced cell death and oxidative stress in PC12 cells. Neurochem Res 36: 2096-2103, 2011.

32. Poulose SM, Miller MG and Shukitt-Hale B: Role of walnuts in maintaining brain health with age. J Nutr 144 (Suppl): 561S-566S, 2014.

33. Heckler MM and Riggins RB: ERR $\beta$ splice variants differentially regulate cell cycle progression. Cell Cycle 14: 31-45, 2015.

34. Liang CC, Park AY and Guan JL: In vitro scratch assay: A convenient and inexpensive method for analysis of cell migration in vitro. Nat Protoc 2: 329-333, 2007.

35. Timm M, Saaby L, Moesby L and Hansen EW: Considerations regarding use of solvents in in vitro cell based assays. Cytotechnology 65: 887-894, 2013.

36. Ammann KR, DeCook KJ, Li M and Slepian MJ: Migration versus proliferation as contributor to in vitro wound healing of vascular endothelial and smooth muscle cells. Exp Cell Res 376: 58-66, 2019.

37. D'Angeli F, Scalia M, Cirnigliaro M, Satriano C, Barresi V, Musso N, Trovato-Salinaro A, Barbagallo D, Ragusa M, Di Pietro C, et al: PARP-14 promotes survival of mammalian $\alpha$ but not $\beta$ pancreatic cells following cytokine treatment. Front Endocrinol (Lausanne) 10: 271, 2019.

38. Clinical and Laboratory Standards Institute: Performance standards for antimicrobial susceptibility testing; Twenty-seventh informational supplement M100-S28. 28th edition. CLSI, Wayne, PA, 2018.

39. Li W, Li V, Ward C, Müller W and Ackermann M: Comparative antiproliferative and antiangiogenic activity of cacao preparations (P06-048-19). Curr Dev Nutr: doi:10.1093/cdn/nzz031. P06-048-19.

40. Poroikov VV and Filimonov DA: How to acquire new biological activities in old compounds by computer prediction. J Comput Aided Mol Des 16: 819-824, 2002. 
41. Filimonov DA, Lagunin AA, Gloriozova TA, Rudik AV Druzhilovskii DS, Pogodin PV and Poroikov VV: Prediction of the biological activity spectra of organic compounds using the pass online web resource. Chem Heterocycl Compd 50: 444-457, 2014.

42. Goel RK, Singh D, Lagunin A and Poroikov V: PASS-assisted exploration of new therapeutic potential of natural products. Med Chem Res 20: 1509-1514, 2011.

43. Kim S, Thiessen PA, Bolton EE, Chen J, Fu G, Gindulyte A, Han L, He J, He S, Shoemaker BA, et al: PubChem substance and compound databases. Nucleic Acids Res 44 (D1): D1202-D1213, 2016.

44. Lagunin AA, Dubovskaja VI, Rudik AV, Pogodin PV, Druzhilovskiy DS, Gloriozova TA, Filimonov DA, Sastry NG and Poroikov VV: CLC-Pred: A freely available web-service for in silico prediction of human cell line cytotoxicity for drug-like compounds. PLoS One 13: e0191838, 2018.

45. Regueiro J, Sánchez-González C, Vallverdú-Queralt A Simal-Gándara J, Lamuela-Raventós R and Izquierdo-Pulido M: Comprehensive identification of walnut polyphenols by liquid chromatography coupled to linear ion trap-Orbitrap mass spectrometry. Food Chem 152: 340-348, 2014

46. Li L, Tsao R, Yang R, Liu C, Zhu H and Young JC: Polyphenolic profiles and antioxidant activities of heartnut (Juglans ailanthifolia Var. cordiformis) and Persian walnut (Juglans regia L.). J Agric Food Chem 54: 8033-8040, 2006.

47. Iasnaia Maria de Carvalho T, Nogueira TYK, Mauro MA Gómez-Alonso S, Gomes E, Da-Silva R, Hermosín-Gutiérrez I and Lago-Vanzela ES: Dehydration of jambolan [Syzygium cumini (L.)] juice during foam mat drying: Quantitative and qualitative changes of the phenolic compounds. Food Res Int 102: 32-42, 2017

48. Norheim F, Gjelstad IM, Hjorth M, Vinknes KJ, Langleite TM, Holen T, Jensen J, Dalen KT, Karlsen AS, Kielland A, et al: Molecular nutrition research: The modern way of performing nutritional science. Nutrients 4: 1898-1944, 2012.

49. Day RL, Harper AJ, Woods RM, Davies OG and Heaney LM Probiotics: Current landscape and future horizons. Future Sci OA 5: FSO391, 2019.

50. Nasri H, Baradaran A, Shirzad H and Rafieian-Kopaei M: New concepts in nutraceuticals as alternative for pharmaceuticals. Int J Prev Med 5: 1487-1499, 2014.

51. Vivarelli S, Salemi R, Candido S, Falzone L, Santagati M, Stefani S, Torino F, Banna GL, Tonini G and Libra M: Gut microbiota and cancer: From pathogenesis to therapy. Cancers (Basel) 11: 11, 2019

52. Amiot-Carlin MJ: Fruit and vegeTable consumption: What benefits, what risks? Rev Prat 69: 139-142, 2019 (In French).

53. Prokopiou E, Kolovos P, Georgiou C, Kalogerou M, Potamiti L, Sokratous K, Kyriacou K and Georgiou T: Omega-3 fatty acids supplementation protects the retina from age-associated degeneration in aged C57BL/6J mice. BMJ Open Ophthalmol 4: e000326, 2019.

54. Ciofu O, Smith S and Lykkesfeldt J: Antioxidant supplementation for lung disease in cystic fibrosis. Cochrane Database Syst Rev 10: CD007020, 2019.

55. Banna GL, Torino F, Marletta F, Santagati M, Salemi R, Cannarozzo E, Falzone L, Ferraù $\mathrm{F}$ and Libra M: Lactobacillus rhamnosus GG: An overview to explore the rationale of its use in cancer. Front Pharmacol 8: 603, 2017.

56. Tiffon C: The impact of nutrition and environmental epigenetics on human health and disease. Int J Mol Sci 19: 19, 2018.

57. Filetti V, Falzone L, Rapisarda V, Caltabiano R, Eleonora Graziano AC, Ledda C and Loreto C: Modulation of microRNA expression levels after naturally occurring asbestiform fibers exposure as a diagnostic biomarker of mesothelial neoplastic transformation. Ecotoxicol Environ Saf 198: 110640, 2020.

58. Falzone L, Lupo G, La Rosa GRM, Crimi S, Anfuso CD Salemi R, Rapisarda E, Libra M and Candido S: Identification of novel microRNAs and their diagnostic and prognostic significance in oral cancer. Cancers (Basel) 11: 11, 2019.

59. Falzone L, Romano GL, Salemi R, Bucolo C, Tomasello B, Lupo G, Anfuso CD, Spandidos DA, Libra M and Candido S: Prognostic significance of deregulated microRNAs in uveal melanomas. Mol Med Rep 19: 2599-2610, 2019.

60. Falzone L, Scola L, Zanghì A, Biondi A, Di Cataldo A, Libra M and Candido S: Integrated analysis of colorectal cancer microRNA datasets: Identification of microRNAs associated with tumor development. Aging (Albany NY) 10: 1000-1014, 2018 .
61. Hardman WE and Ion G: Suppression of implanted MDA-MB 231 human breast cancer growth in nude mice by dietary walnut. Nutr Cancer 60: 666-674, 2008.

62. Hardman WE: Walnuts have potential for cancer prevention and treatment in mice. J Nutr 144 (Suppl): 555S-560S, 2014.

63. Alasalvar C, Salvadó JS and Ros E: Bioactives and health benefits of nuts and dried fruits. Food Chem 314: 126192, 2020.

64. Tibullo D, Caporarello N, Giallongo C, Anfuso CD, Genovese C, Arlotta C, Puglisi F, Parrinello NL, Bramanti V, Romano A, et al: Antiproliferative and antiangiogenic effects of Punica granatum juice (PGJ) in multiple myeloma (MM). Nutrients 8: 8, 2016.

65. Acquaviva R, Menichini F, Ragusa S, Genovese C, Amodeo A, Tundis R, Loizzo MR and Iauk L: Antimicrobial and antioxidant properties of Betula aetnensis Rafin. (Betulaceae) leaves extract. Nat Prod Res 27: 475-479, 2013.

66. Acquaviva R, Genovese C, Amodeo A, Tomasello B, Malfa G, Sorrenti V,Tempera G, Addamo AP, Ragusa S, Rosa T, et al: Biological activities of Teucrium flavum L., Teucrium fruticans L., and Teucrium siculum Rafin crude extracts. Plant Biosyst 152: 720-727, 2018

67. Genovese C, D'Angeli F, Attanasio F, Caserta G, Scarpaci KS and Nicolosi D: Phytochemical composition and biological activities of Orobanche crenata Forssk.: A review. Nat Prod Res: doi:10.10 80/14786419.2020.1739042.

68. Malfa GA, Tomasello B, Acquaviva R, Genovese C, La Mantia A, Cammarata FP, Ragusa M, Renis M and Di Giacomo C: Betula etnensis raf. (Betulaceae) extract induced HO-1 expression and ferroptosis cell death in human colon cancer cells. Int J Mol Sci 20: 20, 2019

69. Salimi M, Majd A, Sepahdar Z, Azadmanesh K, Irian S, Ardestaniyan MH, Hedayati MH and Rastkari N: Cytotoxicity effects of various Juglans regia (walnut) leaf extracts in human cancer cell lines. Pharm Biol 50: 1416-1422, 2012.

70. Rusu ME, Fizesan I, Pop A, Mocan A, Gheldiu AM, Babota M, Vodnar DC, Jurj A, Berindan-Neagoe I, Vlase L, et al: Walnut (Juglans regia L.) Septum: Assessment of bioactive molecules and in vitro biological effects. Molecules 25: 25, 2020.

71. Castro-LópezC, Ventura-Sobrevilla JM, González-HernándezMD, Rojas R, Ascacio-Valdés JA, Aguilar CN and Martínez-Ávila GCG: Impact of extraction techniques on antioxidant capacities and phytochemical composition of polyphenol-rich extracts. Food Chem 237: 1139-1148, 2017.

72. Bi D, Zhao Y, Jiang R, Wang Y, Tian Y, Chen X, Bai S and She G: Phytochemistry, bioactivity and potential impact on health of juglans: The Original plant of walnut. Nat Prod Commun 11: 869-880, 2016

73. Li L, Song L, Sun X, Yan S, Huang W and Liu P: Characterisation of phenolics in fruit septum of Juglans regia Linn. by ultra performance liquid chromatography coupled with Orbitrap mass spectrometer. Food Chem 286: 669-677, 2019.

74. Alañón ME, Oliver-Simancas R, Gómez-Caravaca AM, Arráez-Román D and Segura-Carretero A: Evolution of bioactive compounds of three mango cultivars (Mangifera indica L.) at different maturation stages analyzed by HPLC-DAD-q-TOF-MS. Food Res Int 125: 108526, 2019.

75. Wafa BA, Makni M, Ammar S, Khannous L, Hassana AB Bouaziz M, Es-Safi NE and Gdoura R: Antimicrobial effect of the Tunisian Nana variety Punica granatum L. extracts against Salmonella enterica (serovars Kentucky and Enteritidis) isolated from chicken meat and phenolic composition of its peel extract. Int J Food Microbiol 241: 123-131, 2017.

76. Spatafora $C$ and Tringali C: Natural-derived polyphenols as potential anticancer agents. Anticancer Agents Med Chem 12: 902-918, 2012

77. Carvalho M,Ferreira PJ, Mendes VS, Silva R, Pereira JA, Jerónimo C and Silva BM: Human cancer cell antiproliferative and antioxidant activities of Juglans regia L. Food Chem Toxicol 48: 441-447, 2010.

78. Napoli S, Scuderi C, Gattuso G, Bella VD, Candido S, Basile MS, Libra M and Falzone L: Functional roles of matrix metalloproteinases and their inhibitors in melanoma. Cells 9: 9, 2020.

79. Park JS: Walnut husk ethanol extract possess antioxidant activity and inhibitory effect of matrix metalloproteinase-1 expression induced by tumor necrosis factor alpha in human keratinocyte. Asian J Beauty Cosmetol 11: 715-719, 2013.

80. Loftus JP, Belknap JK and Black SJ: Matrix metalloproteinase-9 in laminae of black walnut extract treated horses correlates with neutrophil abundance. Vet Immunol Immunopathol 113: 267-276, 2006

81. Ma S, Huang D, Zhai M, Yang L, Peng S, Chen C, Feng X, Weng $\mathrm{Q}$, Zhang $\mathrm{B}$ and $\mathrm{Xu} \mathrm{M}$ : Isolation of a novel bio-peptide from walnut residual protein inducing apoptosis and autophagy on cancer cells. BMC Complement Altern Med 15: 413, 2015. 
82.Porter AG and Jänicke RU: Emerging roles of caspase-3 in apoptosis. Cell Death Differ 6: 99-104, 1999.

83. Jänicke RU, Ng P, Sprengart ML and Porter AG: Caspase-3 is required for alpha-fodrin cleavage but dispensable for cleavage of other death substrates in apoptosis. J Biol Chem 273: $15540-15545,1998$.

84. Rosengren RJ: Catechins and the treatment of breast cancer: Possible utility and mechanistic targets. IDrugs 6: 1073-1078, 2003.

85.Das A, Banik NL and Ray SK: Flavonoids activated caspases for apoptosis in human glioblastoma T98G and U87MG cells but not in human normal astrocytes. Cancer 116: 164-176, 2010.

86.El Moussaoui A, Jawhari FZ, Almehdi AM, Elmsellem H, Fikri Benbrahim K, Bousta D and Bari A: Antibacterial, antifungal and antioxidant activity of total polyphenols of Withania frutescens.L. Bioorg Chem 93: 103337, 2019.

87. Rhimi W, Ben Salem I, Immediato D, Saidi M, Boulila A and Cafarchia C: Chemical composition, antibacterial and antifungal activities of crude dittrichia viscosa (L.) Greuter leaf extracts. Molecules 22: 22, 2017.

88. Genovese C, Davinelli S, Mangano K, Tempera G, Nicolosi D, Corsello S, Vergalito F, Tartaglia E, Scapagnini G and Di Marco R: Effects of a new combination of plant extracts plus d-mannose for the management of uncomplicated recurrent urinary tract infections. J Chemother 30: 107-114, 2018.

89. Nicolosi D, Tempera G, Genovese C and Furneri PM: Anti-Adhesion activity of A2-type proanthocyanidins (a Cranberry major component) on uropathogenic E. coli and $\mathrm{P}$. mirabilis strains. Antibiotics (Basel) 3: 143-154, 2014.

90. Genovese C, Pulvirenti L, Cardullo N, Muccilli V, Tempera G Nicolosi D and Tringali C: Bioinspired benzoxanthene lignans as a new class of antimycotic agents: Synthesis and Candida spp. growth inhibition. Nat Prod Res 34: 1653-1662, 2018.

91. Amer AM: Antimicrobial effects of egyptian local chicory, Cichorium endivia subsp. pumilum. Int J Microbiol: doi:10.1155/2018/6475072 2018.

92. Auer GK and Weibel DB: Bacterial cell mechanics. Biochemistry 56: $3710-3724,2017$

93. Exner M, Bhattacharya S, Christiansen B, Gebel J, Goroncy-Bermes P, Hartemann P, Heeg P, Ilschner C, Krame A, Larson E, et al: Antibiotic resistance: What is so special about multidrug-resistant Gram-negative bacteria? Gms Hyg Infect Contr: doi:10.3205/dgkh000290.

94. Salmeri M, Motta C, Mastrojeni S, Amodeo A, Anfuso CD, Giurdanella G, Morello A, Alberghina M, Toscano MA and Lupo G: Involvement of PKC $\alpha$-MAPK/ERK-phospholipase $\mathrm{A}(2)$ pathway in the Escherichia coli invasion of brain microvascular endothelial cells. Neurosci Lett 511: 33-37, 2012.
95. Caporarello N, Olivieri M, Cristaldi M, Scalia M, Toscano MA, Genovese C, Addamo A, Salmeri M, Lupo G and Anfuso CD: Blood-brain barrier in a Haemophilus influenzae type a in vitro infection: Role of adenosine receptors A2A and A2B. Mol Neurobiol 55: 5321-5336, 2018.

96. Saraiva AM, Castro RHA, Cordeiro RP, Sobrinho TJSDP, Castro VTNA, Amorim ELC, Xavier HS, Pisciottano MNC: In vitro evaluation of antioxidant, antimicrobial and toxicity properties of extracts of Schinopsis brasiliensis Engl. (Anacardiaceae). Afr J Pharm Pharmacol 5: 1724-1731, 2011.

97. Peng J, Zheng TT, Liang Y, Duan LF, Zhang YD, Wang LJ, He GM and Xiao HT: p-Coumaric acid protects human lens epithelial cells against oxidative stress-induced apoptosis by MAPK signaling. Oxid Med Cell Longev 2018: 8549052, 2018.

98. Sudan S and Rupasinghe HV: Antiproliferative activity of long chain acylated esters of quercetin-3-O-glucoside in hepatocellular carcinoma HepG2 cells. Exp Biol Med (Maywood) 240: 1452-1464, 2015.

99.Zhang Y, Guo Y, Wang M, Dong H, Zhang J and Zhang L: Quercetrin from Toona sinensis leaves induces cell cycle arrest and apoptosis via enhancement of oxidative stress in human colorectal cancer SW620 cells. Oncol Rep 38: 3319-3326, 2017.

100. Cincin ZB, Unlu M, Kiran B, Bireller ES, Baran Y and Cakmakoglu B: Molecular mechanisms of quercitrin-induced apoptosis in non-small cell lung cancer. Arch Med Res 45: 445-454, 2014

101. Tuaeva NO, Falzone L, Porozov YB, Nosyrev AE, Trukhan VM, Kovatsi L, Spandidos DA, Drakoulis N, Kalogeraki A, Mamoulakis $\mathrm{C}$, et al: Translational application of circulating DNA in oncology: Review of the last decades achievements. Cells 8: 8, 2019.

102. Salemi R, Falzone L, Madonna G, Polesel J, Cinà D, Mallardo D, Ascierto PA, Libra M and Candido S: MMP-9 as a Candidate marker of response to BRAF inhibitors in melanoma patients with BRAFV600E mutation detected in circulating-free DNA. Front Pharmacol 9: 856, 2018.

(i) $\Theta$ This work is licensed under a Creative Common ce NC AD Atribution-NonCommercial-NoDerivatives 4.0 International (CC BY-NC-ND 4.0) License. 